\title{
Histone deacetylase inhibition modulates indoleamine 2,3-dioxygenase-dependent DC functions and regulates experimental graft-versus-host disease in mice
}

Pavan Reddy, ${ }^{1}$ Yaping Sun, ${ }^{1}$ Tomomi Toubai, ${ }^{1}$ Raimon Duran-Struuck, ${ }^{2}$ Shawn G. Clouthier, ${ }^{2}$ Elizabeth Weisiger, ${ }^{1}$ Yoshinobu Maeda, ${ }^{1}$ Isao Tawara, ${ }^{2}$ Oleg Krijanovski, ${ }^{1}$ Erin Gatza, ${ }^{2}$ Chen Liu, ${ }^{3}$ Chelsea Malter, ${ }^{1}$ Paolo Mascagni, ${ }^{4}$ Charles A. Dinarello, ${ }^{5}$ and James L.M. Ferrara ${ }^{2}$

1Department of Internal Medicine and 2Department of Pediatrics, University of Michigan Comprehensive Cancer Center, Ann Arbor, Michigan, USA. ${ }^{3}$ Department of Pathology, University of Florida, Gainesville, Florida, USA. ${ }^{4}$ ItalFarmaco S.p.A, Milan, Italy. ${ }^{5}$ Department of Medicine, University of Colorado Health Sciences Center, Denver, Colorado, USA.

\begin{abstract}
Histone deacetylase (HDAC) inhibitors are antitumor agents that also have antiinflammatory properties. However, the mechanisms of their immunomodulatory functions are not known. We investigated the mechanisms of action of 2 HDAC inhibitors, suberoylanilide hydroxamic acid (SAHA) and ITF 2357, on mouse DC responses. Pretreatment of DCs with HDAC inhibitors significantly reduced TLR-induced secretion of proinflammatory cytokines, suppressed the expression of CD40 and CD80, and reduced the in vitro and in vivo allostimulatory responses induced by the DCs. In addition, injection of DCs treated ex vivo with HDAC inhibitors reduced experimental graft-versus-host disease (GVHD) in a murine allogeneic BM transplantation model. Exposure of DCs to HDAC inhibitors increased expression of indoleamine 2,3-dioxygenase (IDO), a suppressor of DC function. Blockade of IDO in WT DCs with siRNA and with DCs from IDO-deficient animals caused substantial reversal of HDAC inhibition-induced in vitro suppression of DC-stimulated responses. Direct injection of HDAC inhibitors early after allogeneic BM transplantation to chimeric animals whose BM-derived cells lacked IDO failed to protect from GVHD, demonstrating an in vivo functional role for IDO. Together, these data show that HDAC inhibitors regulate multiple DC functions through the induction of IDO and suggest that they may represent a novel class of agents to treat immune-mediated diseases.
\end{abstract}

\section{Introduction}

Pharmacological suppression of the immune system has revolutionized the treatment of autoimmune diseases and transplant recipients. Traditionally, lymphocytes have been the primary targets of immunosuppressive drugs (1), but accumulating evidence suggests that DCs are master regulators of immune responses (2). DCs are the sentinels of innate immunity that also function as the most potent APCs. DCs initiate innate immune responses primarily through TLRs, and they shape adaptive immunity through modulation of $\mathrm{T}$ cell responses (3). After transplantation, DCs present alloantigens to $\mathrm{T}$ cells and initiate allogeneic reactions (4). Agents that target both innate and allostimulatory functions of DCs might therefore have therapeutic potential in many immunemediated disease processes.

Chromatin remodeling by the acetylation and deacetylation of histones helps to regulate gene expression. The acetylation of histones is regulated by 2 classes of enzymes: histone acetyltransferases and histone deacetylases (HDACs) (5, 6). HDAC inhibitors modulate the expression of multiple genes and are currently being evaluated as antitumor agents $(6,7)$. Several recent experimental studies

Nonstandard abbreviations used: B6BMDC, BMDC from a C57BL/6 mouse; BMDC, BM-derived DC; BMT, BM transplantation; FACS, fluorescence-activated cell sorting; GVHD, graft-versus-host disease; HDAC, histone deacetylase; IDO, indoleamine 2,3-dioxygenase; MLR, mixed leukocyte reaction; SAHA, suberoylanilide hydroxamic acid; TCD, T cell-depleted.

Conflict of interest: The authors have declared that no conflict of interest exists. Citation for this article: J. Clin. Invest. 118:2562-2573 (2008). doi:10.1172/JCI34712. have demonstrated that HDAC inhibitors can modulate immune responses at concentrations much lower than those needed for antitumor effects (8-12). Suberoylanilide hydroxamic acid (SAHA) and ITF 2357 are 2 such agents; both reversibly hyperacetylate histones by inhibiting HDAC enzymes $(7,13,14)$. Phase I clinical trials have demonstrated that they are well tolerated and have antitumor activity even in patients with advanced solid and hematological tumors whose prior treatments were extensive $(7,15,16)$

We and others have demonstrated that administration of SAHA at the time of allogeneic BM transplantation (BMT) suppresses proinflammatory cytokine production and reduces systemic acute graft-versus-host disease (GVHD), the major toxicity of allogeneic $\operatorname{BMT}(10,17)$. HDAC inhibitors have also been shown to regulate several other inflammatory and immune-mediated diseases $(8,9$, $11,13,18)$. However, the cellular and molecular mechanisms for the immunomodulatory effects of HDAC inhibitors are not yet known. Here we investigated the effects of hydroxamic acid-containing HDAC inhibitors SAHA and ITF 2357 and showed that they regulated the in vitro and in vivo responses of DCs. Mechanistic studies demonstrated that the HDAC inhibitor-mediated regulation was critically dependent, at least in part, on induction of indoleamine 2,3-dioxygenase (IDO; encoded by Indo).

\section{Results}

HDAC inhibitors regulate innate immune responses of DCs. We tested the effects of SAHA on the innate immune responses of DCs that are triggered through TLRs, cell surface molecules that recognize 
A

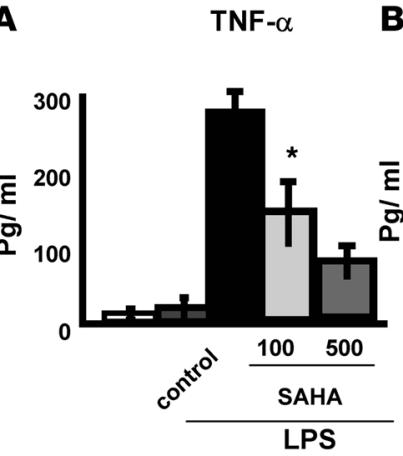

B

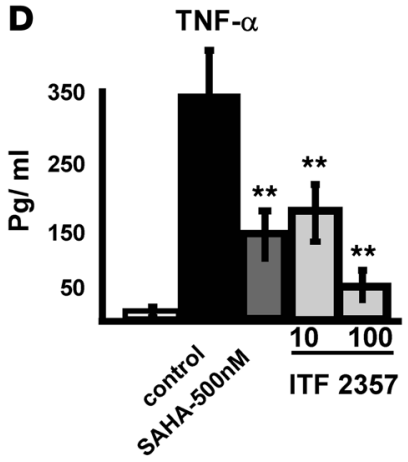

IL-12

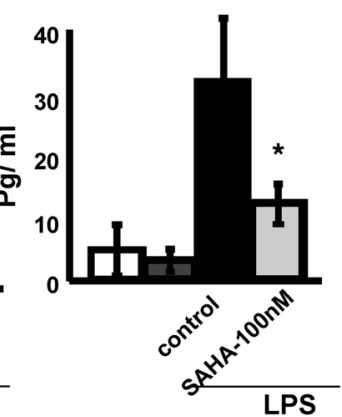

C

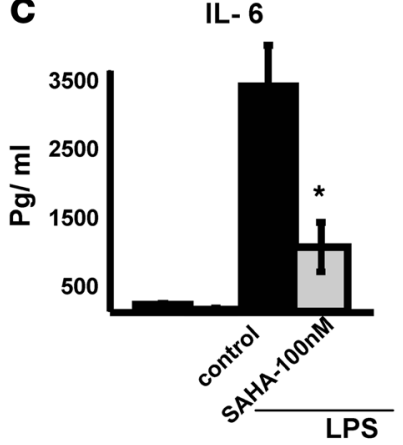

significantly reduced LPS-induced secretion of TNF- $\alpha$ by the peritoneal macrophages (Figure 1E).

We next determined whether SAHA modulated DC responses induced by other TLR ligands. Using IL-6 production as an end point, we found that SAHA attenuated DC function after stimulation with lipoteichoic acid (LTA), a TLR4 ligand, peptidoglycan (PGN), a TLR2 ligand, the dsRNA poly(IC), a TLR3 ligand, and CPG DNA, a TLR9 ligand (Table 1) $(19,20)$. Similar reductions were also seen in the secretion of TNF- $\alpha$ by both SAHA and ITF 2357 (data not shown). Taken together, these data demonstrate that SAHA and ITF 2357 regulate DC and macrophage responses that are mediated through TLR stimulation.

HDAC inhibitors modulate allogeneic T cellstimulatory capacity of DCs. We next determined the effects of HDAC inhibition on in vitro alloresponses by incubating $\mathrm{BALB} / \mathrm{c}$ T cells with allogeneic B6BMDCs in a standard mixed leukocyte reaction (MLR) assay. As shown in Figure 2A, addition of $1 \mu \mathrm{M}$ SAHA or more to the cultures significantly reduced $\mathrm{T}$ cell proliferation at $72 \mathrm{~h}$ by greater than $70 \%$. IL-2 secretion in culture supernatants collected at $48 \mathrm{~h}$ was similarly reduced (Figure 2B).

However, consistent with previous observations (9), SAHA pretreatment did not inhibit $\mathrm{T}$ cell responses after stimulation with anti-CD3 and anti-CD28 (Supplemental Figure 1A). Thus, we reasoned that HDAC inhibition in an MLR might primarily effect DC function. To test this directly, we pretreated BMDCs with different concentrations of SAHA for 16-20 h

pathogen-associated molecular patterns (19). BM-derived DCs (BMDCs) from C57BL/6 mice (B6BMDCs) were incubated with 100 and $500 \mathrm{nM} \mathrm{SAHA}$ for $16-20 \mathrm{~h}$ prior to stimulation with $100 \mathrm{ng} / \mathrm{ml}$ LPS, a potent stimulus of innate immune response via TLR4. SAHAtreated DCs secreted significantly reduced amounts of TNF- $\alpha$, IL-12, and IL-6 in a dose-dependent manner (Figure 1, A-C). We confirmed this effect with a second synthetic HDAC inhibitor that contains hydroxamic acid, ITF 2357. As shown in Figure 1D, pretreatment with 10 and $100 \mathrm{nM}$ ITF 2357 significantly reduced the secretion of TNF- $\alpha$ in response to LPS. These concentrations were chosen because previous data have shown that while these agents have cytotoxic effects at micromolar concentrations, their antiinflammatory effects were observed at lower, nanomolar concentrations $(8,10,13)$. Most subsequent experiments were therefore performed at the nanomolar concentrations described above.

We next investigated whether HDAC inhibitors modulated LPS-mediated responses of other professional APCs, specifically macrophages. Peritoneal cells were harvested from C57BL/ 6 animals and normalized for F4/80 expression. The cells were incubated with diluent (sterile water), SAHA, or ITF 2357 for $16 \mathrm{~h}$ and then stimulated overnight with LPS. Pretreatment with SAHA and then washed them thoroughly prior to use as stimulators in an MLR. As shown in Figure 2C and Figure 3, A and B, pretreatment of DCs at SAHA concentrations of $500 \mathrm{nM}$ or greater significantly reduced allogeneic $\mathrm{T}$ cell proliferation, even with increasing the responder/stimulator ratios (Figure 2C), and also reduced IL-2 secretion by nearly $50 \%$ (Figure 3B). Similar effects were seen upon treatment with ITF 2357 (data not shown). Because cells derived from BM cultures are heterogeneous $(21,22)$, we purified CD $11 c^{+}$DCs by fluorescence-activated cell sorting (FACS) from both C57BL/6 and $\mathrm{BALB} / \mathrm{c}$ BM cultures (>98\% CD11 $\mathrm{c}^{+}$DC purity) and found that SAHA had similar regulatory effects on purified DCs $(62,198 \pm 7,418 \mathrm{cpm}$ versus $29,935 \pm 1,1656 \mathrm{cpm}, P<0.02)$. In contrast, levels of TGF- $\beta$ and IL-10 in MLR supernatants were unchanged (Supplemental Figure 1, B and C), and their neutralization with anti-TGF- $\beta$ or anti-IL-10 mAb did not restore $\mathrm{T}$ cell proliferation in MLRs with SAHA-treated DCs (Figure 3, C and D). Expression of T cell activation markers, such as CD25 and CD69, was also reduced, with no increase in CD152 expression (data not shown).

We then determined whether coculture of naive $\mathrm{T}$ cells with HDAC inhibitor-treated DCs altered their phenotype and/or function into suppressor T cells or Tregs. As shown in Figure 3E, BALB/c 


\section{Table 1}

Effect of SAHA on TLR ligand-mediated secretion of IL-6

\begin{tabular}{lccccc} 
Treatment & Diluent & \multicolumn{4}{c}{ SAHA } \\
Stimulus & None & LTA $(\mathbf{1 0} \mu \mathbf{g} / \mathbf{m l})^{\mathrm{A}}$ & PGN $(\mathbf{1 0} \mu \mathbf{g} / \mathbf{m l})^{\mathrm{B}}$ & poly $(\mathbf{I C})(\mathbf{1 0 0} \mu \mathbf{g} / \mathbf{m l})^{\mathrm{C}}$ & CpG $(\mathbf{1 0} \mu \mathbf{M})^{\mathbf{D}}$ \\
Control DCs & ND & $973 \pm 86$ & $417 \pm 39$ & $528 \pm 67$ & $811 \pm 29$ \\
SAHA DCS & ND & $278 \pm 97^{\mathrm{E}}$ & $63 \pm 24^{\mathrm{F}}$ & $121 \pm 48^{\mathrm{E}}$ & $301 \pm 47^{\mathrm{F}}$
\end{tabular}

DCs were harvested from C57BL/6 BM, treated with either $500 \mathrm{nM} \mathrm{SAHA}$ or diluent control for 16-18 h, and stimulated overnight as indicated. IL- 6 was measured in the culture supernatants at the end of culture with TLR ligands. ND, not detected. Data (mean \pm SEM of triplicate wells) are from 1 of 2 independent experiments with similar results. ${ }^{A} T L R 4$ ligand. BTLR2 ligand. ${ }^{C} T L R 3$ ligand. ${ }^{D T L R 9 ~ l i g a n d . ~}$

$E P<0.02$ versus control DCs. $F P<0.001$ versus control DCs.
T cells from either syngeneic C57BL/6 or allogeneic bm 12 donors (see Methods), which differ from the recipient animals by a single MHC class II antigen. Analysis of donor $\mathrm{T}$ cells in the spleen at $7 \mathrm{~d}$ - chosen because most recipients were dead by $10 \mathrm{~d}-$ revealed fewer $\mathrm{CD}^{+} \mathrm{T}$ cells in animals that received DCs pretreated with SAHA (Figure 3F). We used a similar experimental approach to evaluate the in vivo responses of $\mathrm{CD}^{+}$ $\mathrm{T}$ cells to SAHA-treated DCs in vivo. MHC class I-deficient (HLA- $\mathrm{G}^{-/-}$) recipient mice were conditioned and transplanted as described above with $3 \times 10^{6}$ naive $T$ cells that were incubated in primary cultures with SAHAtreated B6BMDCs proliferated normally in a secondary MLR to the same alloantigen [C57BL/6 (H2 $\left.\left.{ }^{\mathrm{b}}\right)\right]$ and also to a third-party alloantigen, $\mathrm{C} 3 \mathrm{H} / \mathrm{HeJ}\left(\mathrm{H} 2^{\mathrm{k}}\right)$. In addition, these cells did not suppress the proliferation of freshly isolated naive BALB/c T cell responses to $\mathrm{C} 57 \mathrm{BL} / 6$ stimulation at a 1:1 ratio (Figure $3 \mathrm{E}$ ), and no increase in the percent or level of expression of Foxp3 in allogeneic T cells was observed after coculture with SAHA-treated DCs compared with control DCs (data not shown). To determine whether the reduction in allogeneic T cell expansion by SAHA-pretreated DCs was caused by greater apoptosis or by reduced proliferation of the allogeneic $\mathrm{T}$ cells, we performed serial annexin $\mathrm{V}$ staining and CFSE analysis. We cultured CFSE-labeled BABL/c T cells with either HDAC inhibitor-pretreated DCs or control DCs and analyzed the T cells for their proliferative responses or apoptosis by annexin $V$ staining. As shown in Tables 2 and 3, pretreatment of DCs with SAHA reduced allogeneic $\mathrm{T}$ cell proliferation as determined by CFSE staining without causing significant changes in apoptosis.

We next analyzed whether the proliferative responses were restored in the primary MLR cultures with HDAC inhibitor-treated DCs by the addition of exogenous IL-2. As shown in Supplemental Figure 3A, addition of exogenous IL-2 significantly rescued T cell proliferation, suggesting that HDAC inhibitor-treated DCs induced T cell anergy (23). Thus, pretreatment of DCs with HDAC inhibitor did not induce apoptosis of DCs, nor did it trigger regulatory function in T cells cocultured with HDAC inhibitor-treated DCs. We next examined whether SAHA-treated DCs affect the CTL functions of allogeneic $\mathrm{T}$ cells against allospecific targets. BALB/c T cells were stimulated in a bulk MLR with either SAHA-treated or control DCs for $5 \mathrm{~d}$. T cells were harvested and tested for their CTL functions against allogeneic C57BL/6 concanavalin A blasts in a 6-h chromium release killing assay. BALB/c T cells caused equivalent lyses of the allotargets regardless of their stimulation with SAHA or control DCs (Supplemental Figure 3B) and did not cause nonspecific lysis of syngeneic BALB/c concanavalin A blasts (data not shown).

In order to evaluate the effects of HDAC inhibition only on the in vivo function of BM-derived heterogeneous DCs, without the confounding effects on other nonhematopoietic tissues or expression of target antigens, we devised a model in which allogeneic $\mathrm{CD} 4^{+} \mathrm{T}$ cells would respond only to MHC class II alloantigens on exogenously administered DCs in an acute GVHD model. MHC class IIdeficient $\left(\mathrm{Cd} 74^{-/-}\right) \mathrm{C} 57 \mathrm{BL} / 6$ mice $\left(\mathrm{H} 2^{\mathrm{b}}\right)$ received 11 Gy total body irradiation and were injected with $1 \times 10^{7} \mathrm{BMDCs}$ from syngeneic WT C57BL/6 $\left(\mathrm{H}^{\mathrm{b}}\right)$ animals in 2 doses separated by $24 \mathrm{~h}$. We then injected $5 \times 10^{6} \mathrm{~T}$ cell-depleted (TCD) BM along with $2 \times 10^{6} \mathrm{CD} 4^{+}$ allogeneic $\mathrm{CD}^{+} \mathrm{T}$ cells from bm 1 donors (see Methods), which differ from the recipients by a single MHC class I antigen. SAHA pretreatment of DCs also significantly inhibited donor $\mathrm{CD}^{+} \mathrm{T}$ cell proliferation $21 \mathrm{~d}$ after BMT in this model (Figure 3G). Together, these data demonstrate that pretreatment of DCs with SAHA regulates the in vivo alloproliferation of both $\mathrm{CD}^{+}$and $\mathrm{CD}^{+} \mathrm{T}$ cells.

Ex vivo treatment of $D C s$ with $H D A C$ inhibitors regulates experimental $G V H D$. In light of these results, we evaluated whether the regulatory effects of HDAC inhibitor-treated DCs modulated clinically relevant alloresponses by using a well-established murine allogeneic BMT model [BALB/c $\left.\left(\mathrm{H} 2^{\mathrm{d}}\right) \mathrm{C} 57 \mathrm{BL} / 6\left(\mathrm{H} 2^{\mathrm{b}}\right)\right]$, in which activation of donor T cells by host APCs is critical for induction of acute GVHD (24). C57BL/6 Ly5.2 BMT recipients were injected on days $-1,0$, and 2 with $4 \times 10^{6}$ to $5 \times 10^{6}$ host-type B6BMDCs treated with either diluent or $500 \mathrm{nM}$ SAHA for 16-20 h. This schedule was chosen to modulate the initial donor $\mathrm{T}$ cell interaction with host APCs during the first $72 \mathrm{~h}$ after BMT (25-27). As shown in Figure 4A, injection of SAHA-treated DCs to allogeneic animals significantly improved survival compared with injection of control DCs (50\% versus $10 \%$; $P<0.01$ ). We also observed significantly lower GVHD clinical disease scores in mice injected with SAHA-treated DCs compared with controls early after BMT ( $7 \mathrm{~d}, 3.7 \pm 0.2$ versus $5.2 \pm 0.6, P=0.037 ; 14 \mathrm{~d}$, $2.3 \pm 0.4$ versus $4.4 \pm 0.9, P=0.014 ; 21 \mathrm{~d}, 3.1 \pm 0.4$ versus $4.9 \pm 0.8$, $P<0.05 ; 28 \mathrm{~d}, 4.3 \pm 0.7$ versus $5.1 \pm 1 ; P=0.21)$. Consistent with the reduction in clinical GVHD, injection of SAHA-treated DCs also reduced serum levels of TNF- $\alpha$ (Figure 4B) and attenuated the expansion of donor $\mathrm{CD}^{+}$lymphocytes $7 \mathrm{~d}$ after BMT (Figure 4C) (25). We next stained for Foxp 3 on the $\mathrm{H} 2 \mathrm{~d}^{+} \mathrm{CD} 4^{+}$double-positive cells and analyzed for donor CD4 $4^{+} \mathrm{Foxp}^{+}$Treg expansion 7 and $10 \mathrm{~d}$ after allogeneic BMT. There was no significant increase in the percent positivity of donor Tregs in the splenocytes of the recipient aniDC infusion on days 7 and 10 ( $7 \mathrm{~d}, 12.6 \% \pm 3.2 \%$ versus $8.8 \% \pm 3.6 \%$, $P=0.19 ; 10 \mathrm{~d}, 13.1 \% \pm 2.2 \%$ versus $10.4 \% \pm 2.9 \% ; P=0.23)$, suggesting lack of early donor Treg enhancement.

Mechanisms of HDAC inbibitor-mediated regulation of DCs. We explored the cellular mechanisms critical for regulation of DCs mediated by HDAC inhibitors. Although the immunomodulatory effects were observed at low concentrations, because HDAC inhibitors can induce cellular apoptosis (28), we sought to determine whether the regulation of DC function was secondary to loss of $\mathrm{DC}$ viability. We found no significant increase in annexin $\mathrm{V}$-positive CD $11 \mathrm{c}^{+}$DCs when pretreated with 100 and $500 \mathrm{nM}$ SAHA (the dose used for most in vitro studies), but observed a significant increase at 2- and 5- $\mu \mathrm{M}$ concentrations, thus ruling out apoptomals after infusion of SAHA-treated DCs compared with control 


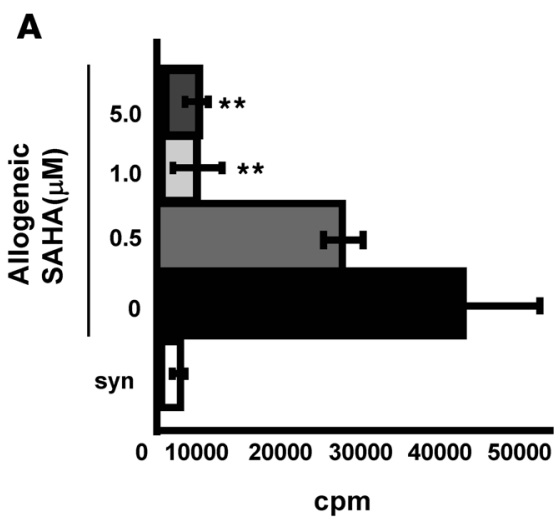

Figure 2

HDAC inhibition modulates allogeneic T cell proliferation and IL-2 production in vitro. SAHA was added at the indicated concentrations to DCs isolated from C57BL/6 BM that were then immediately used as stimulators in an MLR with T cells from either BALB/c (allogeneic) or C57BL/6 (syngeneic) mice as described in Methods. (A) T cell proliferation was determined by ${ }^{3} \mathrm{H}$-thymidine incorporation at $72 \mathrm{~h}$. Allogeneic $\mathrm{T}$ cell responses from control $(0 \mu \mathrm{M}$ SAHA) and SAHA-treated cultures and syngeneic T cell responses to control DCs (syn) are shown. Data are mean \pm SEM of quadruplicate cultures. $P=\mathrm{NS}$, control versus $0.5-\mu \mathrm{M}$ SAHA. ${ }^{* *} P<0.03$ versus control. Results are from 1 of 3 similar experiments. (B) Supernatants of cultures with control (open symbols) or SAHA (filled symbols) were collected at $48 \mathrm{~h}$, and IL-2 was measured by ELISA. Data are mean \pm SEM of quadruplicate cultures. ${ }^{*} P<0.05$ versus control. (C) B6BMDCs were pretreated with diluent or 500 nM SAHA for 16-18 h, washed, and used as stimulators with allogeneic BALB/c T cells at the indicated ratios. T cell proliferation was evaluated after $72 \mathrm{~h}$ of culture. sis as a significant cause of this inhibition at the nanomolar concentrations used to examine the DC immunomodulatory effects (Supplemental Table 1). We next determined whether HDAC inhibitor pretreatment increased the loss of DC viability at later time points. The numbers of DCs recovered were lower in all of the groups at $48 \mathrm{~h}$ after washing away SAHA, including the diluent control group (Supplemental Table 1). However, consistent with annexin $\mathrm{V}$ staining, no statistically significant differences were observed in the retrieval of viable DCs between the control $(0 \mathrm{nM})$ and the 100- and 500-nM groups, but the viability of DCs (annexin $\mathrm{V}$-negative cells) was significantly lower in the DCs treated with micromolar SAHA (Supplemental Table 1).

We also determined whether HDAC inhibitors induced lasting effects on DCs. DCs were thoroughly washed after 14-18 h of incubation with SAHA, allowed to rest for 36-40 h, and then stimulated with $100 \mathrm{ng} / \mathrm{ml}$ LPS after normalizing for the CD $11 \mathrm{c}^{+}$DCs. In contrast to immediate stimulation with LPS following pretreatment with SAHA, no significant decrease in TNF- $\alpha$ was observed between SAHA-treated and control DCs $(329 \pm 78 \mathrm{pg} / \mathrm{ml}$ versus $407 \pm 103 \mathrm{pg} / \mathrm{ml} ; P=0.8)$. These data show that HDAC inhibitors induce marked effects on DC function. However, consistent with the ability of these inhibitors to reversibly inhibit HDAC enzymes, the regulatory effects on DC function may be transient.

We then evaluated the effect of HDAC inhibition on the expression of costimulatory molecules CD80, CD86, and CD40. Control B6BMDCs demonstrated high expression of CD80, CD86, and CD40, as reported previously $(29,30)$, and stimulated proliferation of allogeneic T cells. HDAC inhibitor treatment markedly reduced the surface expression of all these molecules (Figure 5). These data suggest that treatment of DCs with HDAC inhibitors causes active downregulation of costimulatory molecule expression.

To test the potential clinical applicability of our findings, we evaluated the effect of HDAC inhibitor pretreatment on human PBMC-derived DCs. PBMC-derived DCs from normal healthy volunteers were treated with $500 \mathrm{nM}$ SAHA for $18 \mathrm{~h}$ and then washed prior to using them as stimulators in an allogeneic MLR. SAHA treatment of DCs reduced proliferation and IFN- $\gamma$ secretion by allogeneic responder PBMCs (Supplemental Figure 2, A and B) and, consistent with a recent report (31), significantly reduced the expression of CD40 and CD80 on human PBMC-derived CD11 $\mathrm{c}^{+}$ DCs (Supplemental Figure 2, C and D). Pretreatment with both SAHA and 100 nM ITF 2357 also reduced LPS-induced TNF- $\alpha$ expression from these cells (data not shown).

HDAC inhibitors cause immunodominant regulation of DCs. We explored whether HDAC inhibition would dominantly regulate the function of DCs. SAHA-treated DCs were cocultured at increasing ratios with control DCs, whose numbers were kept constant. As shown in Figure 6A, SAHA-treated DCs significantly inhibited the ability of normal DCs to stimulate allogeneic T cell proliferation when they were cocultured only at a high, $1: 1$ ratio. We next evaluated whether regulation at this high ratio was contact dependent. As shown in Figure 6B, when SAHA-treated DCs were separated from control B6BMDCs and BALB/c allogeneic T cells by transwell, allogeneic $\mathrm{T}$ cells proliferated briskly. These data show that HDAC inhibition dominantly regulates the allostimulation of control DCs in a contact-dependent manner.

Next, to address whether the contact-dependent regulation of HDAC inhibitor-treated DCs requires contact with T cells or control DCs, we devised a 3-cell experiment in which SAHA-treated DCs lacked the capacity to present antigens to $\mathrm{T}$ cells. We reasoned that if regulation depended on contact with control DCs alone, rather than T cells, it would be preserved even if the SAHA-treated DCs were deficient in MHC molecules and thus incapable of direct interaction with responder T cells. Cd74-/- $\left(\mathrm{H} 2^{\mathrm{b}}\right)$ mouse B6BMDCs were treated with SAHA as described above and then cocultured with WT $\left(\mathrm{H} 2^{\mathrm{b}}\right)$ B6BMDCs together with purified BALB/c $\left(\mathrm{H} 2^{\mathrm{d}}\right)$ responder $\mathrm{CD}^{+} \mathrm{T}$ cells in an MLR. Contrary to our hypothesis, allogeneic $\mathrm{CD}^{+} \mathrm{T}$ cells proliferated briskly in this 3-cell experiment (Figure 6C), demonstrating that the critical points of contact in the regulation of $\mathrm{T}$ cell proliferation lie between HDAC inhibi- 
A

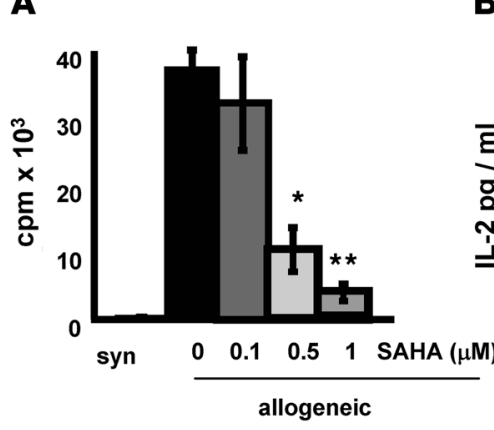

E

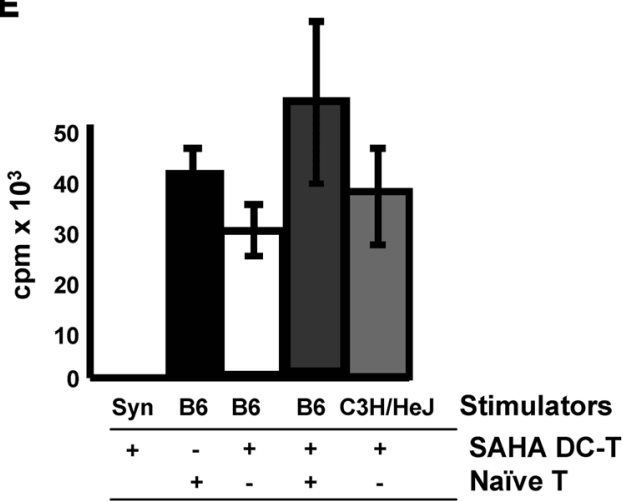

B

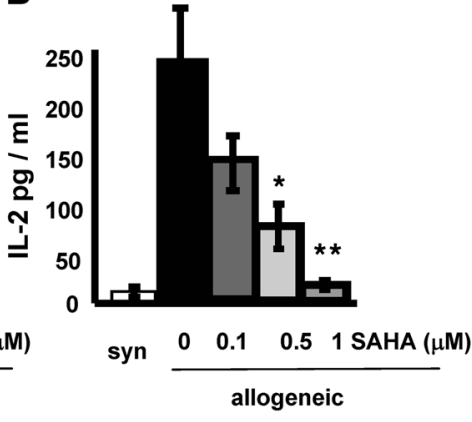

$F$

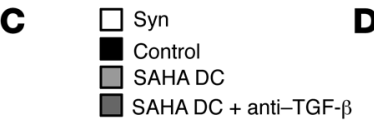

$\begin{array}{ll}\text { D } & \square \text { Syn } \\ \text { Control } \\ \square \text { SAHA DC } \\ \square \text { SAHA DC + anti-IL-10 }\end{array}$

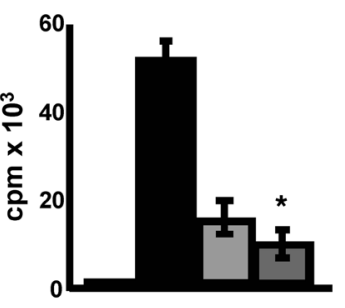

F
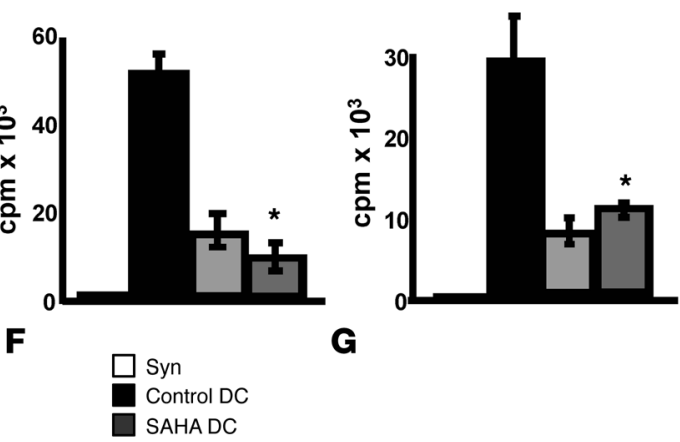

G

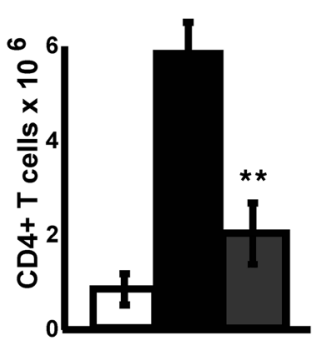

Day +7

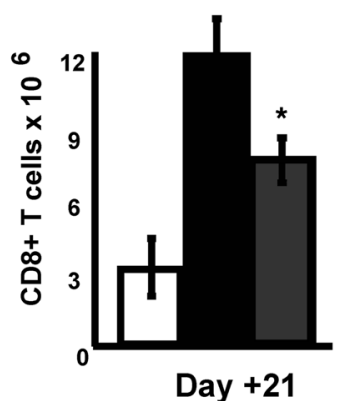

Figure 3

HDAC inhibitors regulate in vitro and in vivo functions of DCs. B6BMDCs were pretreated with diluent or SAHA and used as stimulators in MLR cultures as described in Methods. (A) BALB/c T cell proliferation after $72 \mathrm{~h}$ of culture. (B) IL-2 levels in supernatants at $48 \mathrm{~h}$ of culture. $P=N S$, control versus $0.1 \mu \mathrm{M}$ SAHA. ${ }^{*} P<0.02,{ }^{* *} P<0.01$ versus control. (C and D) Addition of (C) anti-TGF- $\beta$ or (D) anti-IL-10 to SAHA-treated DC cultures did not reverse SAHA-treated DC-mediated suppression. $P=$ NS, SAHA-treated versus control DCs. ${ }^{*} P<0.05$ versus control. (E) Naive BALB/c T cells, or those obtained after $48 \mathrm{~h}$ of culture with C57BL/6 (B6) DCs pretreated with $0.5 \mu \mathrm{M}$ SAHA, were restimulated in secondary cultures with control C57BL/6 DCs either separately or together at a 1:1 ratio. T cells cultured from primary SAHA-treated DCs were restimulated with third-party $\mathrm{C} 3 \mathrm{H} / \mathrm{HeJ} \mathrm{BMDCs} . P=\mathrm{NS}$ for all between-group comparisons. Data are mean $\pm \mathrm{SEM}$ of quadruplicate cultures. $(\mathbf{F}$ and $\mathbf{G})$ Cd74-/- and $H L A-G^{-/-}$animals were irradiated and transplanted as described in Methods. Syngeneic $(n=3-4)$ and some allogeneic animals $(n=4-5)$ received $4 \times 10^{6}$ to $5 \times 10^{6}$ control B6BMDCs, while some allogeneic recipients $(n=5)$ received similar numbers of SAHA-treated B6BMDCs, on days $-1,0$, and 2 relative to BMT. (F) Donor CD4+ cell number was evaluated in recipients' spleens on day $7 .{ }^{* *} P<0.001$ versus allogeneic. Data (mean \pm SEM) are from 1 of 3 similar experiments. (G) Donor CD8 ${ }^{+}$cell number was evaluated in recipients' spleens on day 21. ${ }^{*} P<0.05$ versus allogeneic. Data (mean \pm SEM) are from 1 of 2 similar experiments.

tor-treated DCs and T cells. These data also provide an explanation for the reduction of GVHD by ex vivo-treated DCs we observed and thus collectively show that HDAC inhibition can dominantly regulate the function of DCs both in vitro and in vivo.

HDAC inhibitors induce the expression of IDO. We next sought to determine the potential molecular mechanisms underpinning the regulation of DCs by HDAC inhibitors. IDO is an enzyme that degrades tryptophan, which suppresses DC function and induces $\mathrm{T}$ cell anergy $(32,33)$. Therefore, to elucidate the molecular mechanism of the effect of HDAC inhibition on DC responses, we tested the hypothesis that treatment of DCs with HDAC inhibitors enhances the expression of IDO. B6BMDCs were harvested and treated overnight with increasing concentration of SAHA or ITF 2357; the controls were treated with diluent alone. Cells were harvested and analyzed for the induction of IDO mRNA by RT-PCR, as described in Methods. As shown in Figure 7A, both SAHA and ITF 2357 increased the expression of IDO mRNA, which suggests that HDAC inhibition increases the transcription of IDO. We confirmed the presence of IDO protein by Western blot analysis using these same cellular preparations (data not shown), which suggests that the regulatory effects of HDAC inhibitors on DCs correlates with increased expression of the immunoregulatory enzyme IDO. We next evaluated whether HDAC inhibitors regulate the transcription of IDO by performing a chromatin immunoprecipitation assay (see Methods). As shown in Supplemental Figure 4A, acetylated $\mathrm{H} 4$ was bound to the IDO promoter, demonstrating a direct role for acetylation of histones in promoting transcription of IDO by SAHA.

IDO is critical for HDAC inbibitor-mediated regulation of DCs. To address whether IDO is critical for HDAC inhibitor-mediated regulation of DCs, we used 3 distinct but complementary approaches with siRNA, with pharmacologic inhibition by 1-MT, and with DCs from $I n d 0^{-/-}$mice $(34,35)$. B6BMDCs were treated with $500 \mathrm{nM}$ SAHA, $10 \mathrm{ng} / \mathrm{ml}$ IFN- $\gamma$, or diluent and were transfected with either IDO-specific or control siRNA as described in Methods. At $48 \mathrm{~h}$, IDO-specific siRNA efficiently silenced the mRNA expression of IDO both in the SAHA group and in IFN- $\gamma$-treated controls (Figure 7B). The lack of effect of siRNA on the increased expression of SOD2 in IFN- $\gamma$-treated cells further confirmed the specificity of the silencing of Indo gene expression. 


\section{Table 2}

Effect of HDAC inhibitor pretreatment of DCs on allogeneic T cell apoptosis, determined by annexin $\mathrm{V}$ staining

\begin{tabular}{lccc} 
Treatment & Day $\mathbf{3}$ & Day $\mathbf{5}$ & Day $\mathbf{6}$ \\
Control & $10.95 \pm 0.3175$ & $11.43 \pm 5.895$ & $9.500 \pm 1.365$ \\
SAHA & $10.30 \pm 0.2887$ & $13.33 \pm 1.411$ & $15.83 \pm 8.587$ \\
\hline
\end{tabular}

CD90+ $T$ cells from BALB/c mice were cultured with B6BMDCs pretreated with either diluent or $500 \mathrm{~nm}$ SAHA for $12-16 \mathrm{~h}$ at a 4:1 ratio. T cells were harvested and stained with FITC-conjugated annexin $V$ and allophycocyanin-conjugated CD3 for FACS analysis. Differences were not significant between groups on all days: $3 \mathrm{~d}, P=0.88 ; 5 \mathrm{~d}, P=0.11$; $6 \mathrm{~d}, P=0.51$. Data (mean \pm SEM) are from 1 of 2 similar experiments.

We directly examined the functional role of IDO in mediating the effects of SAHA by measuring the response of DC production of TNF- $\alpha$ to LPS stimulation. B6BMDCs were treated with SAHA or diluent, transfected with either scrambled siRNA control or IDO-specific siRNA, and then stimulated with LPS for the last $12 \mathrm{~h}$ of a 48-h culture (see Methods). TNF- $\alpha$ levels were measured in the supernatants to determine DC function as described above. As we observed in Figure 1A, SAHA treatment suppressed TNF- $\alpha$ production by more than $70 \%$ (Figure $7 \mathrm{C}$ ). Blockade of IDO by siRNA significantly, but not completely, reversed this suppression of TNF- $\alpha$ production by SAHA-treated DCs (Figure 7C). Marked reversal of suppression of the allogeneic $\mathrm{T}$ cell proliferation was also observed when IDO was knocked down (data not shown).

We further confirmed the critical role of IDO in HDAC inhibitormediated regulation by stimulating BMDCs from $\mathrm{Indo}^{-/-}$mice and B6BMDCs with LPS. We observed significantly less suppression of TNF- $\alpha$ secretion by SAHA-treated Indo ${ }^{-/-}$B6BMDCs (Figure 7D), confirming a substantial role for IDO in HDAC inhibitor-mediated suppression of DCs. The role for functional IDO expression by HDAC inhibitor treatment of DCs in the suppression of allogeneic $\mathrm{T}$ cell proliferation was further confirmed by cotreatment with 1-MT (data not shown). Thus, IDO directly mediates, at least in part, the regulation of DCs by HDAC inhibitors.

We next determined whether the effects of HDAC inhibitortreated DCs modulated in vivo GVHD responses in an IDO-dependent manner. We once again used the same allogeneic BMT model (BALB/c into C57BL/6), in which activation of donor T cells by host APCs are critical for induction of acute GVHD. C57BL/ 6 Ly5.2 recipients were injected on days $-1,0$, and 2 relative to $B M T$ with $4 \times 10^{6}$ to $5 \times 10^{6}$ host-type B6BMDCs derived from Indo ${ }^{-/}$animals that were treated with either diluent or $500 \mathrm{nM}$ SAHA for $18 \mathrm{~h}$. As shown in Figure 8, A and B, injection of SAHA-treated Indo ${ }^{-/-}$DCs to allogeneic animals did not alter the survival or the clinical severity of GVHD compared with control-treated Indo-/- DCs (32.1\% versus $12.9 \%$; $P=0.72$ ), demonstrating that induction of IDO in DCs by HDAC inhibition is critical for regulating DC function.

Next, to directly demonstrate the in vivo relevance of IDO induction by HDAC inhibitors, we first confirmed in naive C57BL/ 6 mice the dose and schedule of ITF 2357 sufficient to reach the required drug levels in vivo for induction of IDO. Mouse splenocytes were harvested after administration of either $5 \mathrm{mg} / \mathrm{kg}$ ITF 2357 or the diluent control for $4 \mathrm{~d}$ and analyzed for IDO expression by PCR. As shown in Supplemental Figure 4B, admin- istration of ITF 2357 induced IDO in vivo, which suggests that sufficient tissue and plasma levels of the drug were obtained to evaluate for the role of IDO induction.

We then generated C57BL/6 BM chimeras using TCD BM from Indo $o^{-/} \mathrm{C} 57 \mathrm{BL} / 6$ mice transplanted into recipient $\mathrm{C} 57 \mathrm{BL} / 6$

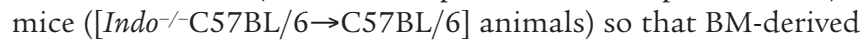
APCs would be incapable of IDO expression. Chimeras were reirradiated on day -1 relative to $B M T$, then injected on day 0 with $\mathrm{TCD} \mathrm{BM}$ and $3 \times 10^{6}$ purified $\mathrm{CD}^{+} \mathrm{T}$ cells from either allogeneic $\mathrm{BALB} / \mathrm{c}$ or syngeneic $\mathrm{C} 57 \mathrm{BL} / 6$ donors. The allogeneic recipients were injected with either diluent or $5 \mathrm{mg} / \mathrm{kg}$ ITF 2357 on days -1 , 0,1 , and 2 relative to BMT in order to modulate the host hematopoietic-derived APCs that initiate graft-versus-host reaction (27). As expected, all allogeneic BALB/c $\rightarrow[\mathrm{C} 57 \mathrm{BL} / 6 \rightarrow \mathrm{C} 57 \mathrm{BL} / 6]$ mice treated with diluent died of GVHD (Figure 8C), while $50 \%$ of allogeneic animals that received ITF 2357 died, and survivors demonstrated mild clinical GVHD (Figure 8, C and D). Conversely, all allogeneic $\left[\right.$ Indo $\left.{ }^{-/-} \mathrm{C} 57 \mathrm{BL} / 6 \rightarrow \mathrm{C} 57 \mathrm{BL} / 6\right]$ recipients died of GVHD, regardless of treatment with ITF 2357 (Figure 8, C and D). However, no significant survival difference was noted between the control-treated $[\mathrm{C} 57 \mathrm{BL} / 6 \rightarrow \mathrm{C} 57 \mathrm{BL} / 6]$ and $\left[\right.$ Indo $^{-/-} \mathrm{C} 57 \mathrm{BL} / 6 \rightarrow$ C57BL/6] animals. GVHD was also confirmed by target organ histopathology (i.e., gastrointestinal tract and liver; data not shown). These data collectively demonstrate that expression of IDO by host APCs alone was not critical for the modulation of GVHD in control-treated animals but was critical for HDAC inhibitormediated regulation of GVHD.

\section{Discussion}

HDAC inhibitors possess potent antitumor properties at high concentrations (36); however, at lower concentrations they modulate many immune responses $(8,9,11,12,37-39)$. Histone acetylation is critical in regulating gene expression for many immune processes (40), but the exact cellular effects and the molecular mechanisms that are critical for immunosuppression caused by these agents are not well understood. Because DCs are master regulators of immunity, they are attractive potential targets for modulating immune reactions. In this study we showed that pretreatment of DCs with SAHA and ITF 2357 modulated murine BMDC functions in vitro and in vivo and also regulated in vitro functions of human PBMCderived DCs. HDAC inhibitors increased the mRNA expression of immunoregulatory enzyme IDO (32), which peaked by $6 \mathrm{~h}$ and returned to baseline by $36 \mathrm{~h}$ (data not shown) and coincided with the transient, but immunodominant, regulation of DCs by HDAC inhibitors. Chromatin immunoprecipitation assay demonstrated that HDAC inhibitors directly enhanced IDO transcription

\section{Table 3}

Effect of HDAC inhibitor pretreatment of DCs on allogeneic T cell proliferation, determined by CFSE staining

$\begin{array}{lcccc}\text { Treatment } & \text { Day } \mathbf{3} & \text { Day } \mathbf{4} & \text { Day } \mathbf{5} & \text { Day } \mathbf{6} \\ \text { Control } & 20.05 \pm 0.02887 & 28.50 \pm 1.222 & 45.77 \pm 5.387 & 51.17 \pm 0.4410 \\ \text { SAHA } & 15.75 \pm 0.1443^{A} & 23.40 \pm 1.250^{A} & 25.97 \pm 0.2333^{A} & 39.00 \pm 1.400^{A}\end{array}$

CD90+ T cells from BALB/c mice were cultured with B6BMDCs pretreated with either diluent or $500 \mathrm{~nm}$ SAHA for $12-16 \mathrm{~h}$ at a 4:1 ratio. T cells were harvested and stained with FITC-conjugated annexin $\mathrm{V}$ and allophycocyanin-conjugated CD3 for FACS analysis. Data are mean \pm SEM. ASignificantly different from control: $3 \mathrm{~d}$, $P=0.025 ; 4 \mathrm{~d}, P=0.043 ; 5 \mathrm{~d}, P=0.003 ; 6 \mathrm{~d}, P=0.001$. 

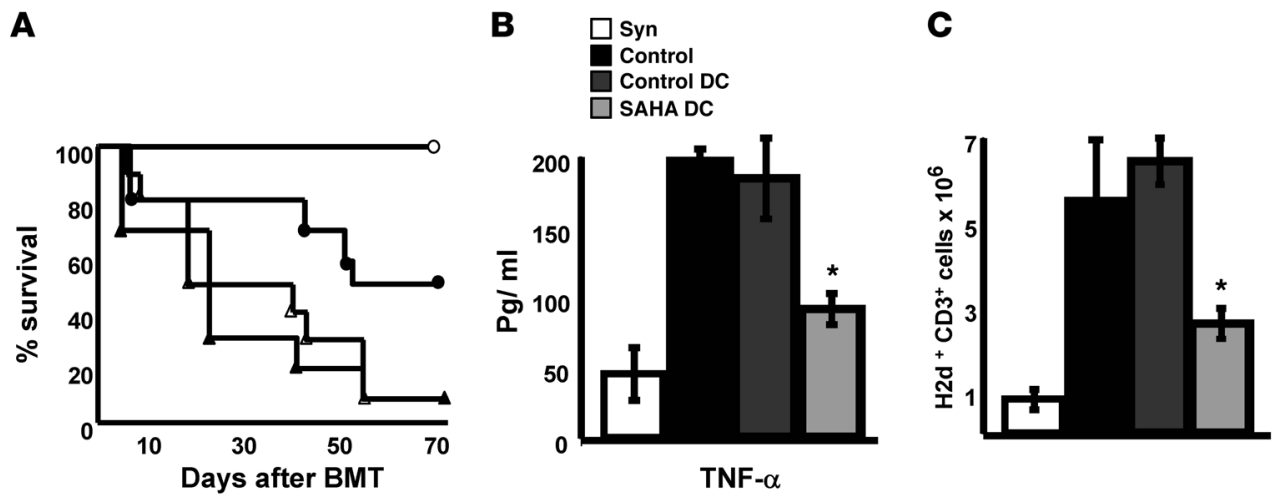

\section{Figure 4}

BMDCs treated ex vivo with HDAC inhibitor regulate acute GVHD. C57BL/6 animals were irradiated and transplanted with TCD BM and T cells from either allogeneic BALB/c or syngeneic C57BL/6 Ly5.2 $(n=4)$ animals as described in Methods. Allogeneic recipients were injected with diluent $(n=10)$ or with $4 \times 10^{6}$ to $5 \times 10^{6}$ control $(n=10)$ or SAHA-treated $(n=10)$ B6BMDCs on days $-1,0$, and 2 relative to BMT. (A) Survival. Open circles, syngeneic; open triangles, diluent-injected allogeneic; filled circles, SAHA-treated DC-injected allogeneic; filled triangles, control DC-injected allogeneic. $P<0.05$, SAHA-treated DCs versus control DCs. (B) Serum levels of TNF- $\alpha 7 \mathrm{~d}$ after BMT. ${ }^{*} P<0.05$ versus allogeneic control recipients. (C) Day-7 donor T cell expansion. ${ }^{*} P<0.05$ versus allogeneic control recipients. Data (mean \pm SEM) were combined from 2 experiments and represent 2 of 3 experiments with similar results.

through acetylation of histone $\mathrm{H} 4$. Gene silencing with siRNA, pharmacologic inhibition with 1-MT, and use of Indo-/- mice confirmed functional relevance for IDO. We thus confirm and extend recent observations on the regulation of DC function by HDAC inhibition and additionally demonstrate what we believe to be a novel molecular mechanism and in vivo relevance for HDAC inhibitor-mediated modulation of DCs $(31,39,41)$. Given the impact of acetylation on gene transcription and protein functions, it is nonetheless possible that HDAC inhibitors will also affect other targets in addition to IDO in the DCs. Furthermore, although IDO is constitutively expressed by $\mathrm{B} 220^{+} \mathrm{CD} 19^{+} \mathrm{CD} 11 \mathrm{c}^{\text {low }}$ plasmacytiod DCs, it can also be induced in a variety of other cell types (42). Because BM-derived DCs contained less than $1 \% \mathrm{~B} 220^{+} \mathrm{CD} 19^{+} \mathrm{CD} 11 \mathrm{c}^{+}$cells (data not shown), our findings suggest that HDAC inhibitors induce expression of IDO primarily in the nonplasmacytiod DC fraction of BMDCs. Nonetheless, the effect of HDAC inhibition on different DC subsets, the additional molecular targets, and the critical pathways that modulate IDO-dependent mechanisms will warrant further studies.

Host DCs, proinflammatory cytokines, donor $\mathrm{T}$ cell responses, and TLR (LPS) signaling play critical roles in the pathogenesis of acute GVHD (43), the most serious complication of allogeneic BMT (44). Injection of host-type DCs treated ex vivo with the HDAC inhibitor SAHA early after BMT significantly controlled acute GVHD mortality. Direct administration of a second HDAC inhibitor, ITF 2357, also reduced acute GVHD that was dependent, at least in part, on the expression of IDO by host-type APCs in response to HDAC inhibition. These data thus confirm a critical role for host expression of IDO and additionally provide what we believe to be a novel molecular mechanism for our and others' previous observations regarding the ability of these agents to suppress GVHD $(10,45)$. Furthermore, our data were suggestive, but not conclusive, that HDAC inhibitors might also have direct salutary effects on epithelial cells during both alloimmune and autoimmune responses $(17,18)$. Thus, direct administration of HDAC inhibitors to BMT recipients could affect not only APCs, but other immune cells (46), and also the epithelial target tissues
$(17,18)$. A recent study suggested an association between histone acetylation and regulation of STAT-1 expression in GVHD in some target organs (18); however, a direct cause and effect relationship of STAT-1 regulation by HDAC inhibition for GVHD protection remains to be demonstrated.
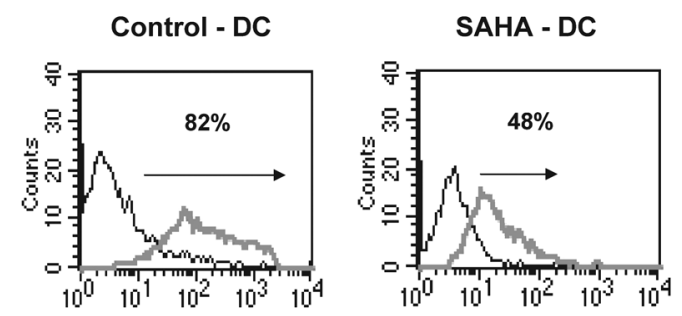

CD80
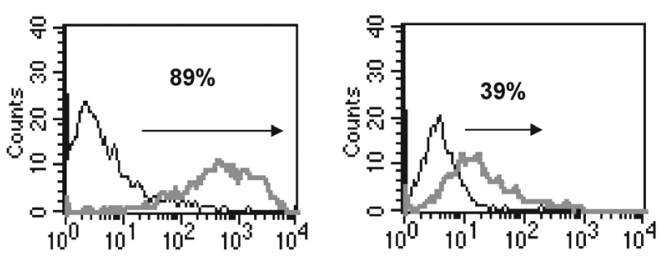

CD86
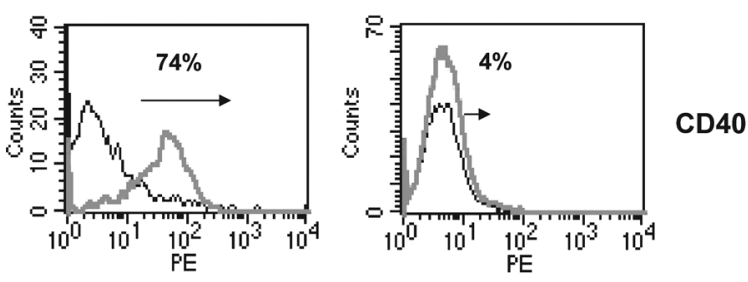

Figure 5

Effect of SAHA on the phenotype of murine DCs. BM cultures enriched for DCs from C57BL/6 mice were sorted by FACS for CD11 $\mathrm{C}^{+}$DCs after being stained with FITC-conjugated anti-CD11c. Cells were then incubated with $0.5 \mu \mathrm{M} \mathrm{SAHA}$ or diluent for $16-18 \mathrm{~h}$ and stained for PE-labeled IgG (black) or anti-CD80, anti-CD86, and anti-CD40 (gray) as described in Methods. Increased expression relative to control IgG is shown by arrows and percentages. Results are representative of 3 replicate experiments. 
A

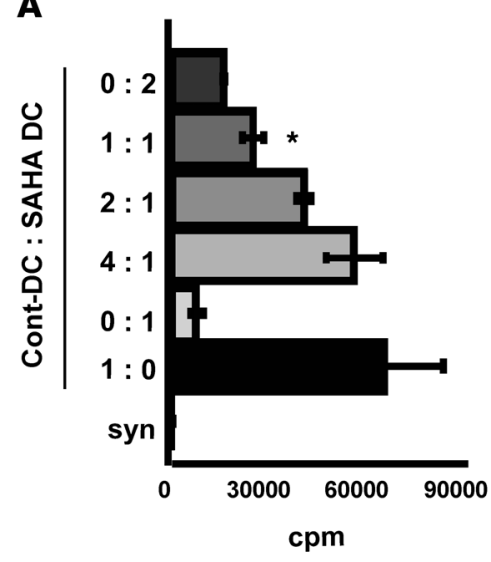

B

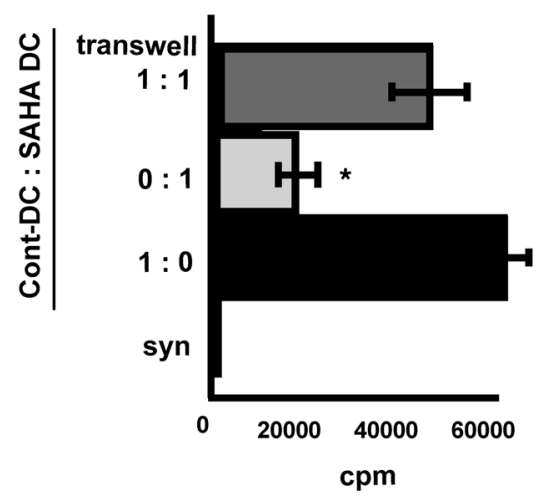

C

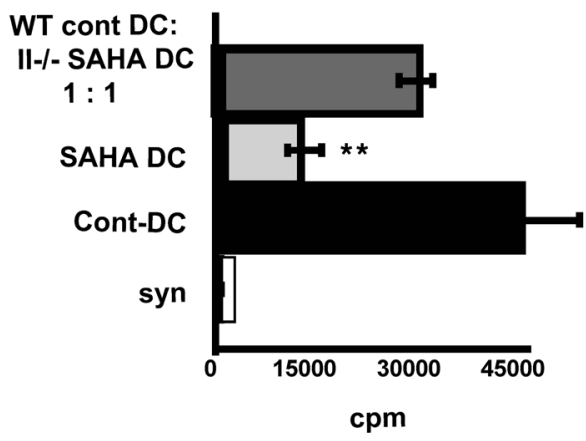

Figure 6

HDAC inhibitor-treated DCs regulate T cell proliferation induced by normal DCs. BMDCs were obtained and treated with SAHA as described in Methods. Control and SAHA-treated DCs were cocultured with allogeneic T cells at the indicated ratios as described in Methods. (A) Coculture at a 1:1 ratio reduced T cell proliferation at $72 \mathrm{~h} .{ }^{*} P<0.05$ versus 1:0 ratio. (B) Separation of the control DCs and SAHA DCs at a 1:1 ratio in a transwell caused robust T cell proliferation. $P=$ NS, $1: 1$ versus 1:0. ${ }^{*} P<0.05$ versus 1:0 ratio. (C) Coculture of control DCs from WT C57BL/6 and SAHA-treated DCs from Cd74-/- animals at a 1:1 ratio caused BALB/c CD4+ T cell proliferation. $P=\mathrm{NS}$, control DCs versus $1: 1 .{ }^{* *} P<0.01$ versus control DCs. Data are mean \pm SEM.

Importantly, HDAC inhibitors do not suppress the CTL responses to allogeneic tumor targets (10) and increase the immunogenicity of tumors, making them more susceptible to $\mathrm{T}$ cell-mediated cytotoxicity (47-50). Furthermore, treatment of P815 and EL-4 tumor cell lines with subcytotoxic doses of SAHA and ITF 2357 did not increase the expression of IDO (data not shown). Given these differential effects, HDAC inhibitors might enhance graftversus-leukemia by increasing tumor immunogenicity (48-50) and maintaining CTL responses while simultaneously reducing GVHD through regulation of DC functions and proinflammatory cytokine secretion. Nonetheless, IDO can be expressed in a variety of other cell types $(32,51-53)$, and how HDAC inhibitors affect the expression of IDO in other cells, and the interactions amongst these cells, remains to be explored.

Immunomodulatory agents, such as IL-10, sirolimus, or vitamin D3, alter the phenotype of DCs by reducing the expression of expression costimulatory molecules, and these agents eventually generate Tregs (54-61). Although HDAC inhibitor treatment of DCs reduced the surface expression of CD40, CD80, and CD86 (31), it did not lead to the generation of the conventional suppressor cells, such as $\mathrm{CD}^{+}{ }^{+} \mathrm{CD} 25^{+} \mathrm{Foxp} 3^{+}$or $\mathrm{Tr}-1$ cells. Moreover, the proliferative responses were restored in the primary MLR cultures by the addition of exogenous IL-2. These data suggest that HDAC inhibitor-treated DCs induced T cell anergy (23) and are consistent with previous observations that IDO-expressing cells induce T cell anergy $(52,53,62,63)$. Recent data show that direct treatment of known Foxp $3^{+}$Tregs with HDAC inhibitors enhances their function and number (46), while our present data showed that HDAC inhibitors had direct effects on DCs that are distinct from the effect of these agents on Tregs. Thus, together with recent observations (64), our present findings suggest that HDAC inhibition can have potent and distinct direct regulatory effects on various immune cells.

Our data on the modulation of murine and human DC phenotype and function by HDAC inhibitors are consistent with previous reports of their effects on human monocyte and macrophage functions (65), but we did not address their effects on non-TLR stimuli or the responses of distinct DC subsets $(22,66)$. It is also important to recognize that various HDAC inhibitors can have qualitatively and quantitatively different - even opposite - effects on cytokine production, depending on the type of stimuli and activation state of target cells as well as the dose and duration of treatment (9).

In summary, our findings demonstrated that the HDAC inhibitors SAHA and ITF 2357 regulated both murine and human DC functions in vitro and regulated experimental GVHD in vivo. Because these agents are relatively well tolerated and are in phase I and phase II clinical trials $(15,16)$, they should soon be ready to be tested as immunoprophylaxis agents in BMT recipients. These data, along with previous observations $(17,18,31,39,41)$, suggest that HDAC inhibitors could be used as therapeutics and also have the potential to modulate cellular therapy. While the outcome of systemic infusion of HDAC inhibitors will likely include a multitude of effects on various cells and tissues, the oral and intravenous availability of these agents may boost their clinical applicability in the future. Furthermore, given their broad immunomodulatory effects on DCs and Tregs (64), these agents may also have important therapeutic potential in other immune-mediated diseases.

It should be noted that in clinical studies that used HDAC inhibitors as antitumor agents, reports of sepsis and hematological alterations were observed, but their immunomodulatory effects have not been well examined $(15,16,67)$. However, one recent study demonstrated that HDAC inhibitors increased virus gene expression but decreased antiviral function of $\mathrm{CD}^{+} \mathrm{T}$ cells in HTLV-1 infection, demonstrating immunological effects of these drugs (68). Nevertheless, our data suggest that the doses needed for immunomodulation are substantially lower than those required for antitumor efficacy, and whether reduced doses alter immune responses need to be determined in well-designed clinical trials.

\section{Methods}

Mice. Female C57BL/6 (K $\left.\mathrm{K}^{\mathrm{b}} \mathrm{D}^{\mathrm{b}}-\mathrm{A}^{\mathrm{b}} \mathrm{I}-\mathrm{E}^{\mathrm{b}} ; \mathrm{CD} 45.2^{+}\right)$, B6.Ly-5a (CD45.1 $\left.{ }^{+}\right), \mathrm{BALB} / \mathrm{c}$ $\left(\mathrm{H} 2^{\mathrm{d}}\right), H L A-G^{-/-} \mathrm{C} 57 \mathrm{BL} / 6\left(\mathrm{H} 2^{\mathrm{b}} ; \mathrm{CD} 45.2^{+}\right), \mathrm{C} 3 \mathrm{H} / \mathrm{HeJ}\left(\mathrm{H} 2^{\mathrm{k}}\right), \mathrm{bm} 12\left(\mathrm{~K}^{\mathrm{b}} \mathrm{D}^{\mathrm{b}} \mathrm{I}-\right.$

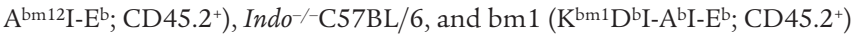


A

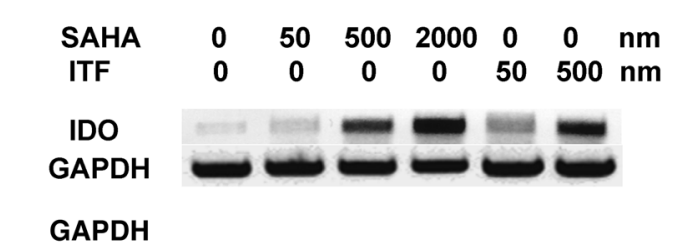

B

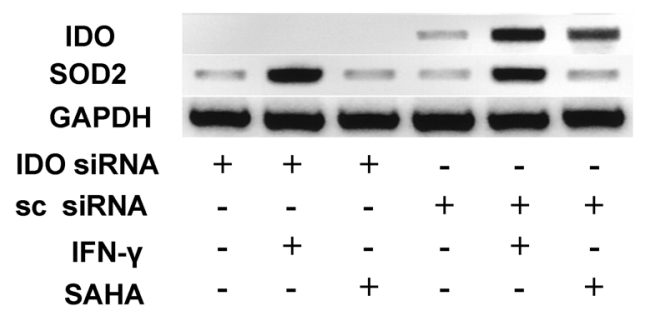

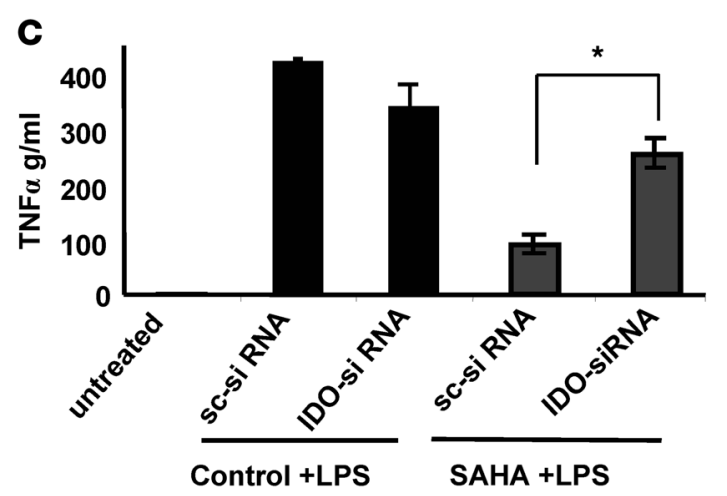

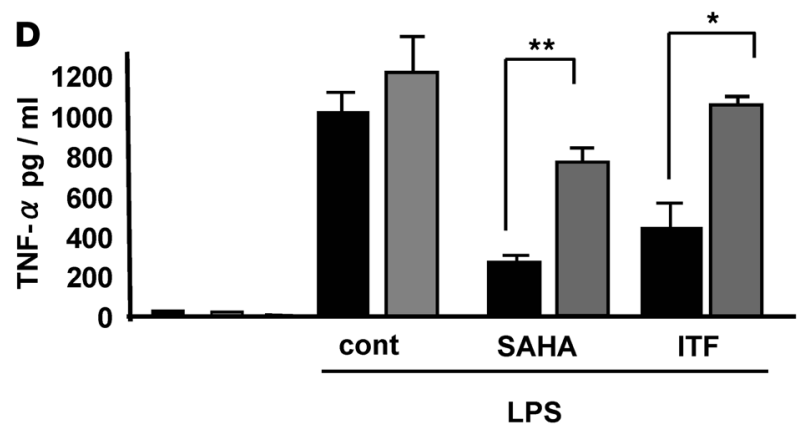

Figure 7

HDAC inhibitors induce IDO and regulate DC function. (A) B6BMDCs were treated with diluent control or with SAHA or ITF 2357 at the indicated concentrations for $16 \mathrm{~h}$, and expression of IDO was evaluated with RT-PCR for IDO mRNA. GAPDH was used to control for RNA loading. Data are from 1 of 2 similar experiments. (B) Blockade of IDO with siRNA. BMDCs were transfected with IDO-specific siRNA or control scrambled (sc) siRNA and treated with diluent control, $500 \mathrm{nM}$ SAHA, or $10 \mathrm{ng} / \mathrm{ml} \mathrm{IFN-} \gamma$. Knockdown of IDO mRNA was evaluated with RT-PCR as described in A. SOD2 expression by IFN- $\gamma$ was used as control for the specificity of IDO knockdown, and GAPDH was used to control for RNA loading. (C) BMDCs were transfected with IDO-specific or control siRNA and treated with either diluent or SAHA as described above. LPS was added for the last $18 \mathrm{~h}$ of culture, and TNF- $\alpha$ was measured in the supernatants. Data (mean \pm SEM) are from 1 of 3 similar experiments. (D) BMDCs were obtained from either WT C57BL/6 or Indo-/- C57BL/6 mice. Cells were treated with diluent, SAHA, or ITF 2357 and stimulated overnight with control media or LPS, after which TNF- $\alpha$ was measured in the supernatants. Data (mean $\pm \mathrm{SEM}$ ) are from 1 of 2 similar experiments. ${ }^{\star} P<0.05$; ${ }^{* \star} P<0.03$.

mice were purchased from The Jackson Laboratory. C57BL/6-background Cd74-/- mice (B6.129-Abb $\left.{ }^{\mathrm{tm} 1} \mathrm{~N} 5 ; \mathrm{CD} 45.2^{+}\right)$were purchased from Taconic Farms. The bm12 and bm1 mice possess mutant MHC class II and MHC class I alleles, respectively, that differ from C57BL/6 mice. The age of mice used for experiments ranged between 8 and $12 \mathrm{wk}$. Mice were housed in sterilized microisolator cages and received filtered water and normal chow or autoclaved hyperchlorinated drinking water for the first $3 \mathrm{wk}$ after BMT. All animals were cared for under regulations reviewed and approved by the University Committee on Use and Care of Animals of the University of Michigan, based on University Laboratory Animal Medicine guidelines.

DC isolation. To obtain DCs, BM cells from C57BL/6 mice were cultured with murine recombinant GM-CSF $(10 \mathrm{ng} / \mathrm{ml}$; BD Biosciences Pharmingen) and $10 \mathrm{ng} / \mathrm{ml} \mathrm{IL-4} \mathrm{(Peprotech)} \mathrm{for} \mathrm{5-8} \mathrm{d} \mathrm{and} \mathrm{harvested} \mathrm{as}$ described previously (69). DCs from normal healthy human volunteers were also isolated from fresh heparinized blood following culture with human IL-4 and GM-CSF for $7 \mathrm{~d}$, as described previously (70). Studies with human cells were performed after obtaining informed consent from the participants and were approved by the University of Michigan Institutional Review Board.

HDAC inbibitors. SAHA and ITF2357 were obtained from Italfarmaco (Cinisello Balsamo) in the form of dry lyophilized powder and were stored at $-80^{\circ} \mathrm{C}$. Vials of SAHA and ITF 2357 were first dissolved in $50 \mu \mathrm{l}$ DMSO, diluted in sterile $\mathrm{H}_{2} \mathrm{O}$, and heated to boiling for complete dissolution before being adding to the cultures (14). DCs were harvested and either sorted or normalized for CD $11 \mathrm{c}^{+} \mathrm{DCs}$ and cultured for $16-18 \mathrm{~h}$ with various concentrations of SAHA and ITF 2357. Sterile $\mathrm{H}_{2} \mathrm{O}$ was used as the diluent control.
Cell cultures. The TLRs on DCs were stimulated overnight with specific pathogen-associated molecular patterns: $1 \mu \mathrm{g}-100 \mathrm{ng} / \mathrm{ml} \mathrm{LPS} \mathrm{and} 10 \mu \mathrm{g} / \mathrm{ml}$ LTA, both for TLR4; $10 \mu \mathrm{g} / \mathrm{ml}$ PGN for TLR2; $100 \mu \mathrm{g} / \mathrm{ml}$ poly(IC) for TLR3; and $10 \mu \mathrm{M}$ CPG for TLR9. The supernatant from the cultures was analyzed for proinflammatory cytokines, including TNF- $\alpha$, IL-12p70, and IL-6. For analysis of proliferative responses, mixed lymphocyte cultures were performed with $2 \times 10^{6}$ cells $/ \mathrm{ml}$ of allogeneic BALB $/ \mathrm{c} \mathrm{CD} 90^{+} \mathrm{T}$ cells cultured in flat-bottomed 96-well Falcon plates (BD) in the presence of SAHA- or control-treated CD $11 \mathrm{c}^{+}$DCs $\left(2 \times 10^{5}\right.$ cells $\left./ \mathrm{ml}\right)$ from C57BL $/ 6$ animals for $72 \mathrm{~h}$, or cultivated with or without $1 \mu \mathrm{g} / \mathrm{ml}$ anti-CD3e and anti-CD28 $\mathrm{mAb}$ (BD Biosciences) for $48 \mathrm{~h}$ by incorporation of $\left[{ }^{3} \mathrm{H}\right]$ thymidine $(1 \mu \mathrm{Ci}$; NEN Life Sciences Products) for the last $24 \mathrm{~h}$ of incubation (69). Transwell experiments were performed with BALB/c T cells and unsorted control C57BL $/ 6$ DCs at $5 \times 10^{5}$ cells $/ \mathrm{ml}$ in the presence of SAHA-treated DCs at $5 \times 10^{5}$ cells $/ \mathrm{ml}$ in the same well or separated by the Transwell (Corning Costar). Proliferative responses were measured after incorporation of $\left[{ }^{3} \mathrm{H}\right]$ thymidine for the last $24 \mathrm{~h}$ of incubation. For proliferative analysis, BALB/c $\mathrm{CD} 90^{+} \mathrm{T}$ cells were labeled with CFSE and cultured with B6BMDCs. These DCs had been pretreated with diluent or $500 \mathrm{~nm}$ SAHA for 16-18 h, washed, and placed in an MLR culture with CFSE-labeled allogeneic T cells as stimulators. T cells were harvested and stained with allophycocyaninconjugated CD3 for CFSE fluorescence intensity analysis.

Cytotoxicity assay. BALB/c T cells from mice were stimulated in bulk primary cultures with control- or SAHA-pretreated B6BMDCs at $37^{\circ} \mathrm{C}$ in a $5 \% \mathrm{CO}_{2}$ atmosphere for $6 \mathrm{~d}$ and used as effector cells after normalizing for $\mathrm{CD}^{+} \mathrm{T}$ cell numbers. C57BL/ 6 or BALB/c spleen cells $\left(2 \times 10^{7}\right)$ were cultured with concanavalin A (Sigma-Aldrich) at a concentration of $5 \mu \mathrm{g} / \mathrm{ml}$ 
A

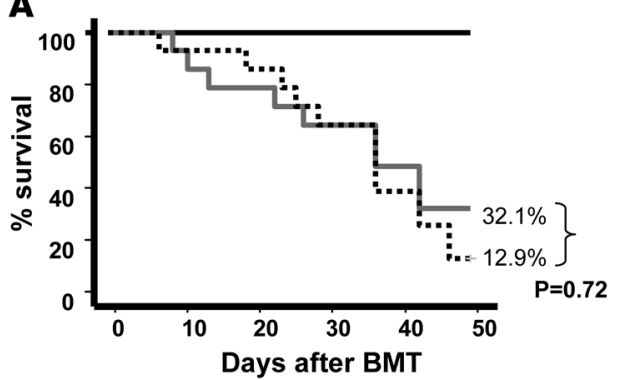

C

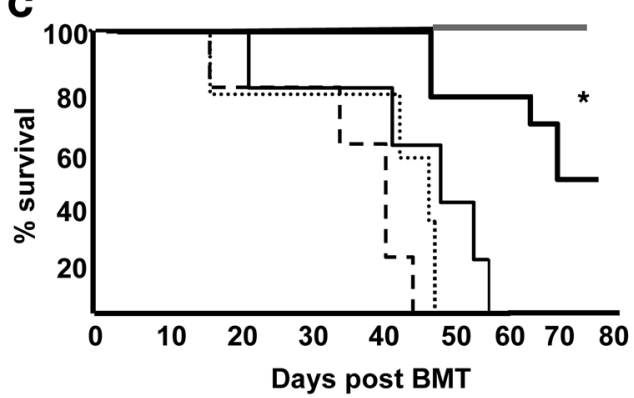

B

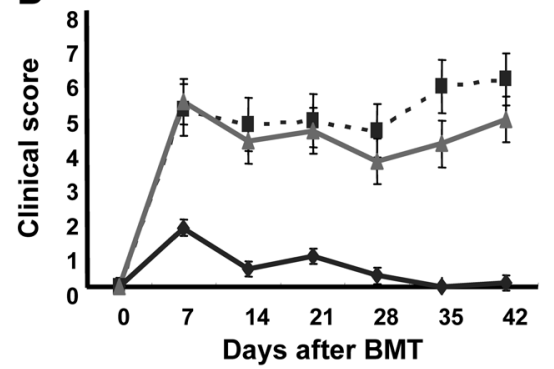

D

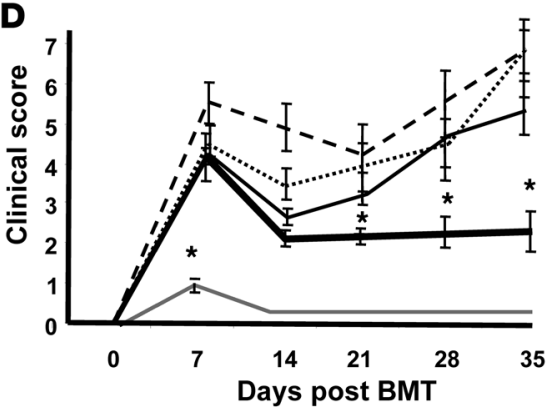

Figure 8

IDO is critical for regulation of GVHD by HDAC inhibitors. (A and B) WT C57BL/6 mice were irradiated and transplanted with TCD BM and T cells from either allogeneic BALB/c or syngeneic C57BL/6 Ly5.2 (black line; $n=8$ ) animals. Allogeneic recipients were injected with $4 \times 10^{6}$ to $5 \times 10^{6}$ of either diluent-treated control (gray line; $n=14$ ) or SAHA-treated (dotted line; $n=14$ ) B6BMDCs from Indo-/ mice on days $-1,0$ and 2 . All mice were evaluated for survival $(\mathbf{A})$ and clinical GVHD severity (B). $P=$ NS, SAHA-treated versus control allogeneic recipients. Data (mean \pm SEM) were combined from 2 experiments with similar results. (C and D) [C57BL/6 $\rightarrow$ C57BL/6] and [C57BL/6 $\rightarrow$ Indo ${ }^{-/}$C57BL/6] chimeras were generated as described in Methods and used as recipients in allogeneic BMT. Chimeras were reirradiated and transplanted with TCD BM and T cells from either allogeneic BALB/C or syngeneic C57BL/6 Ly5.2 (gray line; $n=4$ ) animals. Allogeneic [C57BL/6 $\rightarrow$ C57BL/6] recipients were injected with either diluent (thin line; $n=6$ ) or ITF 2357 (thick line; $n=6$ ) as described in Methods. [C57BL/6 $\rightarrow$ Indo-l-C57BL/6] recipients were also injected with diluent (dotted line; $n=5$ ) or ITF 2357 (dashed line; $n=6$ ). All mice were evaluated for $(\mathbf{C})$ survival and (D) clinical severity of GVHD. ${ }^{*} P<0.05$ versus ITF 2357. Data (mean \pm SEM) are from 1 of 2 similar experiments.

for $3 \mathrm{~d}$ to generate concanavalin A blasts, labeled by incubating $2 \times 10^{6} \mathrm{cells}$ with $2 \mathrm{MBq} \mathrm{Na} 2{ }^{51} \mathrm{CrO}_{4}$ (PerkinElmer) for $1.5 \mathrm{~h}$ at $37^{\circ} \mathrm{C}$ in a $5 \% \mathrm{CO}_{2}$ atmosphere, and used as target cells. After washing, $2.5 \times 10^{3}$ labeled targets were resuspended, and the ${ }^{51} \mathrm{Cr}$-release assay was performed as described previously (71). These preparations were added to quadruplicate wells at varying effector/target ratios and incubated for $6 \mathrm{~h}$. Maximal and background release was determined by the addition of Triton-X 100 (Sigma-Aldrich) or media alone, respectively, to targets. Activity of ${ }^{51} \mathrm{Cr}$ in supernatants taken $6 \mathrm{~h}$ later was determined in an auto-gamma counter (Packard) (71).

Cytokine ELISAs. Concentrations of TNF- $\alpha$, IL-12p70, IL-6, IL-2, IFN- $\gamma$, IL-10, and TGF- $\beta$ were measured in serum or culture supernatants by ELISA with specific anti-mouse mAbs for capture and detection, and the appropriate standards were purchased from BD Biosciences - Pharmingen (IFN- $\gamma$, IL-1, and TNF- $\alpha$ ) and R\&D Systems (IL-12p70, IL-6, IL-2, IL-1, and TGF- $\beta$ ). Assays were performed according to the manufacturer's protocol and read at $450 \mathrm{~nm}$ by using a microplate reader (Bio-Rad).

Cell surface phenotype analysis. To analyze cell surface phenotype, splenocytes or BM cells from naive or transplanted mice were resuspended in PBS and stained with conjugated monoclonal antibodies. FITC-, PE-, or allophycocyanin-conjugated anti-mouse CD11c, CD45.1, CD3, CD8, CD11b, CD25, CD40, CD49, CD80, CD86, and I-A (BD Biosciences - Pharmingen) and FITC- or PE-conjugated anti-human CD11c, CD1a, CD40, and CD80
mAbs (BD Biosciences - Pharmingen) were used for phenotype analyses. Briefly, cells were preincubated with the rat anti-mouse FcR mAb 2.4G2 for 15 min at $4{ }^{\circ} \mathrm{C}$ to block nonspecific FCR binding of labeled antibodies and then incubated with the relevant secondary $\mathrm{mAbs}$ for $30 \mathrm{~min}$ at $4^{\circ} \mathrm{C}$. Finally, cells were washed twice with $0.2 \%$ BSA in PBS, fixed with $1 \%$ paraformaldehyde in PBS, and analyzed by an EPICS Elite ESP cell sorter (Beckman Coulter). Irrelevant IgG $\mathrm{Ig}_{2 \mathrm{~b}} \mathrm{mAbs}$ were used as a negative control (69).

$B M D C$ viability. Annexin V staining was performed to evaluate cellular viability, as described previously (26). Briefly, DCs were obtained from C57BL/6 BM cultures, treated with increasing concentrations of SAHA ( 0 , 50,500 , and 2,000 nM), harvested 14-16 h after SAHA treatment, stained with FITCconjugated CD11c, washed with $1 \times \mathrm{PBS}$, and stained with PE-conjugated annexin V (R\&D Systems) in the dark for $15 \mathrm{~min}$ at room temperature in labeling buffer. DC apoptosis was identified based on double staining for CD11c and annexin V. In order to assess $\mathrm{T}$ cell viability, an MLR was set with $\mathrm{CD} 90^{+}$ $\mathrm{T}$ cells from a BALB/c mouse and C57BL/6 DCs pretreated with either $500 \mathrm{~nm}$ SAHA or diluent for $12-16 \mathrm{~h}$ at a $4: 1$ ratio for 3,5 , and $6 \mathrm{~d}$. T cells were harvested and stained with FITC-conjugated annexin V and allophycocyanin-conjugated CD3 for FACS analysis.

RNA isolation and RT-PCR. Total cellular RNA was isolated by using TRIzol reagent (Invitrogen) and then reverse transcribed $(2 \mu \mathrm{g})$ using Moloney murine leukemia virus RT (Promega) and random hexamer primers in a total volume of $20 \mu \mathrm{l}$ at $42^{\circ} \mathrm{C}$ for $60 \mathrm{~min}$. One-tenth of the RT reaction was subjected to PCR analysis using primer pairs specific for IDO (5'-GAAGGATCCTTGAAGACCAC-3' and 5'-GAAGCTGCGATTTCCACCAA-3'), SOD2 (5'-AGACCTGCCTTACGACTATG- $3^{\prime}$ and $5^{\prime}$-AGCGGAATAAGGCCTGTTGT- $3^{\prime}$ ), and glyceraldehyde-3-phosphate dehydrogenase (5'-AAATCCCATCACCATCTTCC-3' and $5^{\prime}$-GTCCACCACCCTGTTGCTGC-3'). PCR products were resolved on $1 \%$ agarose ethidium bromide gels; bands were visualized on a ChemiImager 4400 system (Alpha Innotech Co.); and images were inverted for presentation to show dark bands on a light background.

siRNA synthesis and transfection. The siRNA sequences specific for murine IDO (sense, 5'-GGGCUUCUUCCUCGUCUCUTT-3'; antisense, 5'-AGAGACGAGGAAGAAGCCCTT-3') and the negative scrambled siRNA controls (35) were selected, synthesized, and annealed by the manufacturer (Invitrogen). The transfection of DCs and siRNA for IDO was performed as described previously $(34,35)$. Briefly, $10 \mu \mathrm{g}$ siRNA in $90 \mu \mathrm{l}$ transfection buffer $(20 \mathrm{mM}$ HEPES, $150 \mathrm{mM} \mathrm{NaCl}$; pH 7.4) were mixed in solution made from $60 \mu \mathrm{l}$ 1,2dioleoyl-3-trimethylammonium-propane (DOTAP) according to the manufacturer's instructions (Roche). After incubation at room temperature, the mixture was added to medium containing $3 \times 10^{6} \mathrm{CD} 11 \mathrm{c}^{+} \mathrm{DCs}$ and incubated for $8 \mathrm{~h}$ at $37^{\circ} \mathrm{C}$. The cells were then harvested and placed in fresh medium for an additional $40 \mathrm{~h}$ with or without various doses of SAHA or ITF 2357. Some cells were treated with LPS $(1 \mu \mathrm{g} / \mathrm{ml})$ for the last $12 \mathrm{~h}$ of the incubation 
period. Cells were then recovered, washed, and immediately used for analysis of IDO expression by RT-PCR. Prior to using the IDO-specific siRNA, we tested the transfection efficiency of the above conditions. BLOCK-it Fluorescenct Oligo (Invitrogen), a fluorescein-labeled dsRNA oligomer designed for RNAi transfection analysis, was used to assess and optimize the cationic liposome-mediated transfection of DCs, a good indication of transfection efficiency with our standard siRNA. After $24 \mathrm{~h}$ of transfection, the cells were examined under an inverted reflected-light fluorescence microscope (model 1X70, with filter BA515 for fluorescein; Olympus) and a 100-W high-pressure mercury lamp. Digital images for phase-contrast and FITC were captured by a SPOT Xplorer camera (Diagnostic Instruments Inc.) attached to the microscope. The total number of cells and the number of FITC-labeled cells in the same fields were identified and counted in 10 randomly selected areas per high-power field (original magnification, $\times 100$ ) and revealed that we had a transfection efficiency of $75 \%-90 \%$.

Chromatin immunoprecipitation assay. Chromatin immunoprecipitation assay was performed to evaluate the binding of acetylated histone $\mathrm{H} 4$ to the IDO promoter, as described previously (72). Briefly, cells were cross-linked with $1 \%$ formaldehyde for $30 \mathrm{~min}$, quenched with $1.25 \mathrm{~mm}$ glycine for $5 \mathrm{~min}$, harvested, and washed twice with cold PBS. Cells were resuspended in lysis buffer (50 mm HEPES, pH 8.0; 1 mM EDTA; 0.5 mM EGTA; 140 mM NaCl; $10 \%$ glycerol; 0.55 mM NP-40; $0.25 \%$ Triton X-100; 1 mM PMSF; and $1 \times$ protease inhibitor mixture; Pierce) and sonicated for 5 bursts of $15 \mathrm{~s}$ each, followed by a cooling period of $40 \mathrm{~s}$ in an ice bath using Dimembrator 550 (Fisher Scientific) and centrifugation at $13,000 \mathrm{~g}$ for $10 \mathrm{~min}$. One-tenth of the total lysate was used for total genomic DNA as input control. Supernatant was treated with salmon sperm DNA (Sigma-Aldrich), BSA-coated protein $\mathrm{A} / \mathrm{G}$ agarose (Invitrogen), and rabbit IgG (Santa Cruz Biotechnology Inc.) by incubating at $4^{\circ} \mathrm{C}$ for $1 \mathrm{~h}$ with rocking. Immunoprecipitation was performed for $15 \mathrm{~h}$ at $4^{\circ} \mathrm{C}$ with $4 \mathrm{~g}$ each of rabbit acetylated $\mathrm{H} 4$-specific antibody and control rabbit IgG (Upstate). Protein A/G agarose was added and incubated at $4{ }^{\circ} \mathrm{C}$ for $1 \mathrm{~h}$. Complexes were washed once in low-salt buffer (0.1\% SDS; $1 \%$ Triton X-100; 2 mM EDTA; 20 mM Tris, pH 8.0; and $150 \mathrm{mM} \mathrm{NaCl})$, once in high-salt buffer (0.1\% SDS; $1 \%$ Triton X-100; $2 \mathrm{mM}$ EDTA; $20 \mathrm{mM}$ Tris, $\mathrm{pH} 8.0$; and $500 \mathrm{mM} \mathrm{NaCl}$ ), and once in $\mathrm{LiCl}$ buffer (0.25 M LiCl; $1 \%$ NP-40; $1 \%$ deoxycholate; 1 mM EDTA; and $10 \mathrm{mM}$ Tris, pH 8.0), followed by 2 washes in TE buffer ( $20 \mathrm{mM}$ Tris and $2 \mathrm{mM}$ EDTA). Washed complexes were eluted with freshly prepared elution buffer (1\% SDS and $100 \mathrm{mM} \mathrm{NaHCO}$ ), and the $\mathrm{Na}^{+}$concentration was adjusted to $200 \mathrm{mM}$ to reverse the formaldehyde cross-linking. DNA fragments were then precipitated. For PCR, 21 of a 30-1 DNA extraction was used. PCR primers corresponded to sequences within IDO promoter $\gamma$-IFN-activated site regions as follows: forward, 5'-CTCCTTTTATGGGTGATTGTTTCC-3'; reverse, 5'-GAGAACTCCTAAGTTTATGTCCAC-3'.

$B M T$. BMT was performed according to a standard protocol, as described previously (10). WT C57BL/6, Cd74-/-, or $H L A-G^{-/-}$C57BL/6 mice were irradiated with $11 \mathrm{~Gy}$ total body irradiation $\left({ }^{137} \mathrm{Cs}\right.$ source) on day -1 relative to BMT and were injected with $4 \times 10^{6}$ to $5 \times 10^{6} \mathrm{BM}$-derived host-type (WT C57BL/6 or Indo-/) DCs on days $-1,0$ and 2 or as otherwise specified following total body irradiation. On the day of BMT, mice received $2 \times 10^{6}$ purified splenic $\mathrm{T} \mathrm{CD} 3^{+}$cells along with $5 \times 10^{6} \mathrm{TCD}$ BM cells from either syngeneic or allogeneic BALB/c donors. In experiments with MHC class IIand MHC class I-deficient animals, mice received $2 \times 10^{6} \mathrm{CD} 4^{+} \mathrm{T}$ cells or $3 \times 10^{6} \mathrm{CD}^{+} \mathrm{T}$ cells (along with $5 \times 10^{6} \mathrm{TCD}$ BM cells) from bm 12 or bm1 donors, respectively. In preliminary experiments, administration of $1 \times 10^{6}$ or $2 \times 10^{6} \mathrm{DCs}$ had no significant effects on GVHD severity. BM chimeras using TCD BM from $[\mathrm{C} 57 \mathrm{BL} / 6 \rightarrow \mathrm{C} 57 \mathrm{BL} / 6]$ and $\left[\right.$ Indo ${ }^{-/} \mathrm{C} 57 \mathrm{BL} / 6 \rightarrow$ $\mathrm{C} 57 \mathrm{BL} / 6$ ] animals were generated following irradiation of $11 \mathrm{~Gy}$. After 3-4 mo, these animals were conditioned with $10 \mathrm{~Gy}$ on day -1 and used as recipients in a second BMT with $3 \times 10^{6}$ to $4 \times 10^{6} \mathrm{~T}$ cells and $5 \times 10^{6} \mathrm{BM}$ cells from allogeneic BALB/c donors. The chimeras received $5 \mathrm{mg} / \mathrm{kg}$ ITF 2357 or diluent on days -1 to 2 relative to BMT.

Statistics. Survival curves were plotted using Kaplan-Meier estimates. The Mann-Whitney U-test was used for the statistical analysis of in vitro data and clinical scores, while the Mantel-Cox log-rank test was used to analyze survival data. A $P$ value less than 0.05 was considered statistically significant.

\section{Acknowledgments}

This work was supported by NIH grants K08 AI052863-01 (to P. Reddy), PO1 CA 49542 (to J.L.M. Ferrara), AI-15614 (to C.A. Dinarello), and HL-68743 (to C.A. Dinarello). P. Reddy is the recipient of the Alaina J. Enlow Scholar Award from Amy Strelzer Manasevit - National Marrow Donor Program and the Doris Duke Clinical Scientist Development Award.

Received for publication December 10, 2007, and accepted in revised form May 7, 2008.

Address correspondence to: Pavan Reddy, 6310 CCC, University of Michigan Cancer Center, 1500 East Medical Center Drive, Ann Arbor, Michigan 48109-0942, USA. Phone: (734) 647-5954; Fax: (734)647-9271; E-mail: reddypr@umich.edu.
1. Waldmann, H., and Cobbold, S. 2004. Exploiting tolerance processes in transplantation. Science. 305:209-212.

2. Mellman, I., and Steinman, R.M. 2001. Dendritic cells: specialized and regulated antigen processing machines. Cell. 106:255-258.

3. Medzhitov, R., and Janeway, C.A., Jr. 2002. Decoding the patterns of self and nonself by the innate immune system. Science. 296:298-300.

4. Morelli, A.E., and Thomson, A.W. 2003. Dendritic cells: regulators of alloimmunity and opportunities for tolerance induction. Immunol. Rev. 196:125-146.

5. Narlikar, G.J., Fan, H.Y., and Kingston, R.E. 2002. Cooperation between complexes that regulate chromatin structure and transcription. Cell. 108:475-487.

6. Johnstone, R.W. 2002. Histone-deacetylase inhibitors: novel drugs for the treatment of cancer. Nat. Rev. Drug Discov. 1:287-299.

7. Marks, P.A., Miller, T., and Richon, V.M. 2003. Histone deacetylases. Curr. Opin. Pharmacol. 3:344-351.
8. Leoni, F., et al. 2002. The antitumor histone deacetylase inhibitor suberoylanilide hydroxamic acid exhibits antiinflammatory properties via suppression of cytokines. Proc. Natl. Acad. Sci. U. S. A. 99:2995-3000

9. Skov, S., et al. 2003. Histone deacetylase inhibitors: a new class of immunosuppressors targeting a novel signal pathway essential for CD154 expression. Blood. 101:1430-1438.

10. Reddy, P., et al. 2004. Histone deacetylase inhibitor suberoylanilide hydroxamic acid reduces acute graft-versus-host disease and preserves graft-versus-leukemia effect. Proc. Natl. Acad. Sci. U. S. A. 101:3921-3926.

11. Mishra, N., Reilly, C.M., Brown, D.R., Ruiz, P., and Gilkeson, G.S. 2003. Histone deacetylase inhibitors modulate renal disease in the MRL-lpr/lpr mouse. J. Clin. Invest. 111:539-552.

12. Reilly, C.M., et al. 2004. Modulation of renal disease in MRL/lpr mice by suberoylanilide hydroxamic acid. J. Immunol. 173:4171-4178.

13. Leoni, F., et al. 2005. The histone deacetylase inhibitor ITF2357 reduces production of pro-inflamma- tory cytokines in vitro and systemic inflammation in vivo. Mol. Med. 11:1-15.

14. Carta, S., et al. 2006. Histone deacetylase inhibitors prevent exocytosis of interleukin-1beta-containing secretory lysosomes: role of microtubules. Blood. 108:1618-1626.

15. Kelly, W.K., et al. 2003. Phase I clinical trial of histone deacetylase inhibitor: suberoylanilide hydroxamic acid administered intravenously. Clin. Cancer Res. 9:3578-3588.

16. Kelly, W.K., et al. 2005. Phase I study of an oral histone deacetylase inhibitor, suberoylanilide hydroxamic acid, in patients with advanced cancer. J. Clin. Oncol. 23:3923-3931.

17. Leng, C., et al. 2006. Reduction of graft-versus-host disease by histone deacetylase inhibitor suberonylanilide hydroxamic acid is associated with modulation of inflammatory cytokine milieu and involves inhibition of STAT1. Exp. Hematol. 34:776-787.

18. Glauben, R., et al. 2006. Histone hyperacetylation is associated with amelioration of experimental colitis in mice. J. Immunol. 176:5015-5022.

19. Akira, S. 2003. Mammalian Toll-like receptors. 
Curr. Opin. Immunol. 15:5-11.

20. Kobayashi, K., et al. 2002. RICK/Rip2/CARDIAK mediates signalling for receptors of the innate and adaptive immune systems. Nature. 416:194-199.

21. Dakic, A., et al. 2004. Development of the dendritic cell system during mouse ontogeny. J. Immunol. 172:1018-1027.

22. Shortman, K., and Liu, Y.J. 2002. Mouse and human dendritic cell subtypes. Nat. Rev. Immunol. 2:151-161.

23. Schwartz, R.H. 2003. T cell anergy. Annu. Rev. Immunol. 21:305-334.

24. Sun, K., et al. 2004. Inhibition of acute graft-versushost disease with retention of graft-versus-tumor effects by the proteasome inhibitor bortezomib. Proc. Natl. Acad. Sci. U. S. A. 101:8120-8125.

25. Hill, G.R., et al. 1997. Total body irradiation and acute graft-versus-host disease: the role of gastrointestinal damage and inflammatory cytokines. Blood. 90:3204-3213.

26. Reddy, P., et al. 2001. Interleukin-18 regulates acute graft-versus-host disease by enhancing Fas-mediated donor T cell apoptosis. J. Exp. Med. 194:1433-1440.

27. Zhang, Y., Louboutin, J.P., Zhu, J., Rivera, A.J., and Emerson, S.G. 2002. Preterminal host dendritic cells in irradiated mice prime CD8+ T cell-mediated acute graft-versus-host disease. J. Clin. Invest. 109:1335-1344.

28. Bolden, J.E., Peart, M.J., and Johnstone, R.W. 2006. Anticancer activities of histone deacetylase inhibitors. Nat. Rev. Drug Discov. 5:769-784.

29. Pierre, P., et al. 1997. Developmental regulation of MHC class II transport in mouse dendritic cells. Nature. 388:787-792.

30. Gallucci, S., Lolkema, M., and Matzinger, P. 1999. Natural adjuvants: endogenous activators of dendritic cells. Nat. Med. 5:1249-1255.

31. Nencioni, A., et al. 2007. Histone deacetylase inhibitors affect dendritic cell differentiation and immunogenicity. Clin. Cancer Res. 13:3933-3941.

32. Mellor, A.L., and Munn, D.H. 2004. IDO expression by dendritic cells: tolerance and tryptophan catabolism. Nat. Rev. Immunol. 4:762-774.

33. Munn, D.H., et al. 1998. Prevention of allogeneic fetal rejection by tryptophan catabolism. Science. 281:1191-1193.

34. Fallarino, F., et al. 2004. Murine plasmacytoid dendritic cells initiate the immunosuppressive pathway of tryptophan catabolism in response to CD200 receptor engagement. J. Immunol. 173:3748-3754.

35. Belladonna, M.L., et al. 2006. Kynurenine pathway enzymes in dendritic cells initiate tolerogenesis in the absence of functional IDO. J. Immunol. 177:130-137.

36. Marks, P., et al. 2001. Histone deacetylases and cancer: causes and therapies. Nat. Rev. Cancer 1:194-202.

37. Bohmig, G.A., et al. 1999. Stable prodrugs of nbutyric acid: suppression of $\mathrm{T}$ cell alloresponses in vitro and prolongation of heart allograft survival in a fully allogeneic rat strain combination. Transpl. Immunol. 7:221-227.

38. Suthanthiran, M., Rubin, A.L., Novogrodsky, A., and Stenzel, K.H. 1982. Immunosuppressive properties of polar organic compounds that induce cellular differentiation in Friend erythroleukemia cells. Transplantation. 33:534-540.

39. Brogdon, J., et al. 2007. Histone deacetylase activities are required for innate immune cell control of Th1 but not Th2 effector cell function. Blood. 109:1123-1130.

40. Mostoslavsky, R., Alt, F.W., and Bassing, C.H. 2003. Chromatin dynamics and locus accessibility in the immune system. Nat. Immunol. 4:603-606.

41. Bode, K.A., et al. 2007. Histone deacetylase inhibitors decrease Toll-like receptor-mediated activation of proinflammatory gene expression by impairing transcription factor recruitment. Immunology. 122:596-606

42. Munn, D.H., and Mellor, A.L. 2007. Indoleamine 2,3-dioxygenase and tumor-induced tolerance. J. Clin. Invest. 117:1147-1154.

43. Reddy, P., and Ferrara, J.L. 2003. Immunobiology of acute graft-versus-host disease. Blood Rev. 17:187-194.

44. Reddy, P. 2003. Pathophysiology of acute graft-versus-host disease. Hematol. Oncol. 21:149-161.

45. Jasperson, L.K., et al. 2008. Indoleamine 2,3-dioxygenase is a critical regulator of acute graft-versushost disease lethality. Blood. 111:3257-3265.

46. Tao, R., et al. 2007. Deacetylase inhibition promotes the generation and function of regulatory $\mathrm{T}$ cells. Nat. Med. 13:1299-1307.

47. Zika, E., and Ting, J.P. 2005. Epigenetic control of MHC-II: interplay between CIITA and histonemodifying enzymes. Curr. Opin. Immunol. 17:58-64.

48. Magner, W.J., et al. 2000. Activation of MHC class I, II, and CD40 gene expression by histone deacetylase inhibitors. J. Immunol. 165:7017-7024.

49. Nebbioso, A., et al. 2005. Tumor-selective action of HDAC inhibitors involves TRAIL induction in acute myeloid leukemia cells. Nat. Med. 11:77-84.

50. Insinga, A., et al. 2005. Inhibitors of histone deacetylases induce tumor-selective apoptosis through activation of the death receptor pathway. Nat. Med. 11:71-76.

51. Mellor, A.L., Keskin, D.B., Johnson, T., Chandler, P., and Munn, D.H. 2002. Cells expressing indoleamine 2,3-dioxygenase inhibit $\mathrm{T}$ cell responses. J. Immunol. 168:3771-3776.

52. Munn, D.H., et al. 2004. Expression of indoleamine 2,3-dioxygenase by plasmacytoid dendritic cells in tumor-draining lymph nodes. J. Clin. Invest. 114:280-290.

53. Munn, D.H., et al. 2005. GCN2 kinase in T cells mediates proliferative arrest and anergy induction in response to indoleamine 2,3-dioxygenase. Immunity. 22:633-642.

54. Sato, K., Yamashita, N., Baba, M., and Matsuyama, T. 2003. Regulatory dendritic cells protect mice from murine acute graft-versus-host disease and leukemia relapse. Immunity. 18:367-379.

55. Hackstein, H., Taner, T., Logar, A.J., and Thomson, A.W. 2002. Rapamycin inhibits macropinocytosis and mannose receptor-mediated endocytosis by bone marrow-derived dendritic cells. Blood. 100:1084-1087.

56. Hackstein, H., et al. 2003. Rapamycin inhibits IL-4-induced dendritic cell maturation in vitro and dendritic cell mobilization and function in vivo. Blood. 101:4457-4463.

57. Hackstein, H., and Thomson, A.W. 2004. Dendritic cells: emerging pharmacological targets of immunosuppressive drugs. Nat. Rev. Immunol. 4:24-34.

58. Penna, G., and Adorini, L. 2000. 1 Alpha,25-dihydroxyvitamin D3 inhibits differentiation, maturation, activation, and survival of dendritic cells leading to impaired alloreactive T cell activation. J. Immunol. 164:2405-2411.

59. Griffin, M.D., et al. 2001. Dendritic cell modulation by 1alpha, 25 dihydroxyvitamin D3 and its analogs: a vitamin $\mathrm{D}$ receptor-dependent pathway that promotes a persistent state of immaturity in vitro and in vivo. Proc. Natl. Acad. Sci. U. S. A. 98:6800-6805.

60. Gregori, S., et al. 2001. Regulatory T cells induced by 1 alpha,25-dihydroxyvitamin D3 and mycophenolate mofetil treatment mediate transplantation tolerance. J. Immunol. 167:1945-1953.

61. Adorini, L., Giarratana, N., and Penna, G. 2004. Pharmacological induction of tolerogenic dendritic cells and regulatory $T$ cells. Semin. Immunol. 16:127-134.

62. Anandasabapathy, N., et al. 2003. GRAIL: an E3 ubiquitin ligase that inhibits cytokine gene transcription is expressed in anergic CD4+ T cells. Immunity. 18:535-547.

63. Seroogy, C.M., et al. 2004. The gene related to anergy in lymphocytes, an E3 ubiquitin ligase, is necessary for anergy induction in CD4 T cells. J. Immunol. 173:79-85.

64. Reddy, P., and Zou, W. 2007. Blocking HDACs boosts regulatory T cells. Nat. Med. 13:1282-1284.

65. Bohmig, G.A., et al. 1997. n-butyrate downregulates the stimulatory function of peripheral blood-derived antigen-presenting cells: a potential mechanism for modulating T-cell responses by short-chain fatty acids. Immunology. 92:234-243.

66. Seong, S.Y., and Matzinger, P. 2004. Hydrophobicity: an ancient damage-associated molecular pattern that initiates innate immune responses. Nat. Rev. Immunol. 4:469-478.

67. Duvic, M., et al. 2007. Phase 2 trial of oral vorinostat (suberoylanilide hydroxamic acid, SAHA) for refractory cutaneous T-cell lymphoma (CTCL). Blood. 109:31-39.

68. Mosley, A.J., et al. 2006. Histone deacetylase inhibitors increase virus gene expression but decrease CD8+ cell antiviral function in HTLV-1 infection. Blood. 108:3801-3807.

69. Teshima, T., et al. 2002. Flt3 ligand therapy for recipients of allogeneic bone marrow transplants expands host CD8 alpha(+) dendritic cells and reduces experimental acute graft-versus-host disease. Blood. 99:1825-1832.

70. Jonuleit, H., Schmitt, E., Schuler, G., Knop, J., and Enk, A.H. 2000. Induction of interleukin 10-producing, nonproliferating CD4(+) T cells with regulatory properties by repetitive stimulation with allogeneic immature human dendritic cells. J. Exp. Med. 192:1213-1222.

71. Maeda, Y., et al. 2007. Lymphopenia-induced proliferation of donor $\mathrm{T}$ cells reduces their capacity for causing acute graft-versus-host disease. Exp. Hematol. 35:274-286.

72. Boyd, K.E., and Farnham, P.J. 1999. Coexamination of site-specific transcription factor binding and promoter activity in living cells. Mol. Cell. Biol. 19:8393-8399. 